"This is the peer reviewed version of the following article: [Financial Management, 2017, 46 (3), pp. 553 - 592], which has been published in final form at [doi.org/10.1111/fima.12168]. This article may be used for non-commercial purposes in accordance with Wiley Terms and Conditions for Self-Archiving." 


\title{
Firm Opacity Lies in the Eye of the Beholder
}

\author{
Sandeep Dahiya \\ McDonough School of Business \\ Georgetown University \\ Rafik B. Hariri Building \\ Washington DC 20057 \\ Tel: +(1) 2026873808 \\ E-mail: sd@georgetown.edu \\ Giuliano Iannotta \\ Department of Economics and Business Administration \\ Universita Cattolica \\ Via Necchi 7, 20123 \\ Milano, Italy \\ Tel: +(39)-027234 2912 \\ E-mail: giuliano.iannotta@unicatt.it \\ Marco Navone \\ Finance Discipline Group, UTS Business School \\ University of Technology \\ Sydney, PO Box 123 \\ Broadway NSW 2007 Australia \\ Tel: +(61) 295147736 \\ E-mail: marco.navone@uts.edu.au
}

\begin{abstract}
We classify and test different empirical measures of firm opacity and document multiple theoretical and empirical inconsistencies across these proxies by testing the relative opacity of banks versus non-banks. We evaluate the effectiveness of these proxies by observing the effect of two cleanly identified shocks to firm-specific information, credit rating initiation and inclusion in the S\&P500 index. Using a difference-in-difference approach of comparing newly rated firms (S\&P 500 index) with a propensity matched sample of "unchanged" firms, we show that only the number of analysts and the Amihud's illiquidity ratio (2002) provide consistent patterns across different estimation specifications and different econometric settings. Based on our tests we recommend that these two proxies should be used as the primary measures of firm opacity. These two proxies show that banks are more opaque than non-banks.
\end{abstract}

JEL CLASSIFICATIONS: G19; G21; G24; D89

KEYWORDS: FIRM OPACITY, RATING INITIATION, ANALYSTS' COVERAGE, DIFFERENCE-IN-DIFFERENCE, PROPENSITY SCORE MATCHING 


\section{Firm Opacity Lies in the Eye of the Beholder}

Information asymmetry between contracting agents has been a rich area of research for economists. Theories of asymmetric information form key elements of seminal frameworks about capital structure and corporate governance. ${ }^{1}$ The central theme in this body of research is that outside investors do not enjoy prefect transparency about the inner workings of a firm, which in turn creates a wedge between investors (outsiders) and the manager (insider). "Firm opacity" is usually meant to reflect the level of information asymmetry between insiders and outsiders. Firm opacity/information asymmetry has been used as a motivating factor for a wide variety of economic outcomes in a number of recent studies. ${ }^{2}$

Importantly, firm opacity cannot be observed directly. Empirical researchers typically use a measurable firm characteristic as a proxy for firm opacity in order to test their hypotheses. A quick survey of the recent literature in which firm opacity is either the main variable or one of the control variables shows that there is little consensus on what is (are) the best proxy(ies) for firm opacity. Some authors choose proxies based on information production by third parties such as analysts or rating agencies. The idea is that the existence of a credit rating reduces a firm's opacity as an independent agency produces and disseminates firm-specific information. This reduces information asymmetry faced by potential investors. ${ }^{3}$ Some recent studies that use this approach include Faulkender and Petersen (2006), Sufi (2007), and Bharath, Dahiya, Saunders and Srinivasan (2011). Similarly, the quantity and quality of equity analysts who follow a particular firm is also frequently used as a measure of firm opacity or information asymmetry and some of the recent papers that employ this strategy include Leary and Roberts (2010), Mehran and Peristiani (2010), and Gomes and Phillips (2012). Other papers look at the stock market price behavior: Jin and Myers (2006) argue that firm opacity is correlated with negatively skewed returns and higher co-movements with the market index, and the same intuition is shared by Hutton et al. (2009) and Haggard et al. (2008). Finally, Flannery et al. (2004) argue that opacity increases stock illiquidity, and thus measures of price impact or transaction costs are viable proxies for firm opacity.

This wide range of firm opacity proxy variables creates challenges for an empiricist seeking to examine the impact of firm opacity on economic decisions of interest (e.g. capital structure). The problem is especially acute when we consider the theoretical and empirical inconsistencies

\footnotetext{
${ }^{1}$ For example, the pecking order theory of capital structure (Myers, 1984) uses the information asymmetry between outside investors and inside managers as its motivation.

2 Sufi (2007) shows that bank-loan syndicates tend to be more concentrated for opaque borrowers to ensure tighter lender-monitoring. Gomes and Phillips (2012) show that as the level of information asymmetry increases a firm is more likely to raise capital from private markets.

${ }^{3}$ We use firm opacity and information asymmetry between the firm insiders and outsiders interchangeably.
} 
across these different measures. Consider, for example, the following set of findings reported in recent papers. A high level of co-movement between a firm's stock price and the broad market index (typically estimated as R-square of the regression of firm stock return against the market index return) is considered a sign of a high level of opacity for that firm by some researchers (see Morck et al., 2000 and Jin and Myers, 2006). On the other hand, an increase in the level of analyst coverage is typically assumed to be a sign of increasing transparency (Mehran and Peristiani, 2010). However, Chan and Hameed (2006) show that an increase in analyst coverage (predicting lower firm opacity) is associated with higher R-square (increase in firm opacity)!

There is little empirical work that has compared the effectiveness of these various opacity proxies and their relationship to one another. Our first contribution in this paper is to catalog and compare a number of opacity measures used in previous empirical studies. This is an important issue because if the observed correlation across various proxies is high, it would suggest that they are all measuring similar sources of information opacity. This should mitigate any concerns about the results being driven by the choice of opacity proxy used. However, if these proxies capture unrelated information about firms, the correlation across different measures should be fairly low. In that case, it is possible that empirical tests seeking to explain the variation in firm opacity may be driven, at least partly, by the choice of the "opacity proxy" used by the researcher rather than by any true variations in underlying firm opacity. ${ }^{4}$

Previous studies have employed a fairly large number of opacity proxies. It is unwieldy to catalogue each and every measure so instead we focus on a subset of nine commonly used measures. Our choice of information opacity measures are widely-used not only historically but also in recent papers. Furthermore, we focus on testing different types of proxies. Our selection ensures that each type of proxy is represented in the set we examine in this paper. We use the case of the banking industry as a special case to test different opacity proxies. While the question regarding relative opacity of banks versus non-banks is an important one, we are primarily interested in examining the consistency across different opacity proxies. Thus, if we find that all opacity proxies suggest higher (or lower) opacity for the banks, one can conclude that the relative merits of employing one proxy versus another is likely to be insignificant. However, our analysis of banks versus non-banks shows that these proxies produce inconsistent results - when compared to non-banking firms, some proxies show banks as being more opaque while the others indicate that banks are less opaque. ${ }^{5}$

\footnotetext{
${ }^{4}$ If there are "different types" of opacity, the different proxies may well capture these different information opacities. However, there is little theoretical work to guide an empiricist interested in designing tests to examine such differences.

${ }^{5}$ Our conflicting evidence on bank opacity suggests that the results are highly dependent on the proxy used. We want to stress that the tests of bank opacity suffer from a joint hypothesis problem. A failure to find higher (lower) opacity of banks could be either because of poor choice of opacity proxy or due to lack of a significant difference in the opacity of banks and non-banks.
} 
While the tests of bank opacity highlight the potential pitfall in using a single class of information asymmetry measure to draw broad conclusions, our final set of tests attempt to identify opacity proxies that can used across all industries. Our second major contribution in this paper is to develop a "horse race" to measure the effectiveness of various opacity proxies not just for banking industry but for all industries. It is impossible to measure firm opacity directly and we lack a "true benchmark" against which we can calibrate the measures used in prior research. We use a quasi-experimental approach of identifying firms that are subject to a cleanly identified firm-specific information shock (the "treatment" sample) and estimate the change in pre- and post-shock levels of various opacity measures for this group. Using the propensity score matching methodology (PSM) we identify a "control" group of firms that had the same likelihood of experiencing the shock and estimate the change in pre- and post-shock level of opacity measures for this group. We examine the difference-in-difference (DID) of these opacity measures for the two groups to see if the information shock is indeed accompanied by a significant change in the opacity proxies.

The two information events that we use are the initiation of a credit rating and the inclusion in the S\&P 500 index. We argue that both of these events constitute an empirically clean and identifiable shock to the quality of the information environment faced by an outside investor. Both events are likely to increase the investor base of a firm. Rating initiation is likely to bring on board new bond investors while inclusion in the S\&P 500 is frequently associated with higher institutional ownership. Thus, these events are likely to be accompanied by a subsequent decrease in information opacity. Our justification for using these events does not depend on causation. Our choice of these events should be acceptable as long as there is a significant positive association between rating initiation/index inclusion and reduction in opacity. We acknowledge that obtaining a credit rating is an endogenous firm decision and is likely driven by many underlying firm characteristics which may also affect the information asymmetry between the firm and potential outside investors. Still, it is plausible to argue that a firm receiving a credit rating for the first time experiences a significant reduction in information opacity as ratings constitute a major information gathering and dissemination event. For example, Faulkender and Petersen (2006) show that having a credit rating is almost always associated with the presence of public debt in a firm's capital structure. Inclusion in the S\&P 500 index appears to be exogenous, but the probability of being included in it is not random. Standard \& Poors has a well-defined process for index selection. We mitigate these concerns by creating a matched sample of "control" firms that had a similar likelihood of experiencing these two events. We exploit this discontinuity in the information environment of a firm to test the effectiveness of various opacity proxies. As mentioned earlier, we adopt a difference-in-difference approach. For example, we compare each newly-rated firm with a group of matched "unrated" firms that were as likely (based on 
firm-level and other contemporaneous factors) to have received a rating at the same time. We argue that for newly-rated firms, opacity proxies should differ significantly for the pre-rating and post-rating period. Our results suggest that the number of analysts following a firm and the price impact (as measured by the Amihud's (2002) ratio) appear to be the most consistent across multiple specifications. We repeat these tests for inclusion in the S\&P 500 index and again find that the analysts' coverage and the Amihud measure continue to be significant.

Our paper also provides additional empirical evidence that stock returns synchronicity is not a robust proxy for information opacity. This co-movement is typically measured by the R-square derived from regression of the firm stock returns against the returns of the overall market. How to interpret R-square as a measure for firm opacity has been debated in a number of recent papers. Morck, Yeung, and Yu (2000) and Jin and Myers (2006) argue that a firm with a high R-square is likely to have less firm-specific information in its stock price. This line of argument suggests that higher R-square implies higher firm opacity. However, Kelly (2014) finds that low R-square stocks appear to have the greatest degree of information asymmetry compared to their high R-square counterparts. Similarly, Dasgupta, Gan, and Gao (2010) show that stock return synchronicity is significantly higher for older (arguably less opaque) firms. Furthermore, they report that after a disclosure of substantial information during SEOs and ADR listings (i.e. a decrease in firm opacity), the R-square goes up. Chan, Hameed, and Kang (2013) find a positive relation between stock return synchronicity and liquidity. Our tests show that high R-square is not associated with high information opacity. Thus, a key result of our paper is to provide

additional support for the findings of Kelly (2014) which show that R-Square is not a reliable opacity measure.

The paper is laid out in the following manner. We discuss the different opacity measures in the next section. Section 3 provides an overview of empirical studies that have examined the opacity of banks compared to non-banks and motivates our choice of using the banking industry to study this issue. We discuss our data in section 4 and present our main results in section 5. Section 6 summarizes and concludes.

\section{Different measures of firm opacity}

A number of recent studies have used a wide variety of empirical proxies to measure firm opacity. The proxies we chose to test are relatively straightforward to construct as they are based on datasets commonly used in empirical finance work. Also, the construction methodology of these measures is well-established and widely disseminated. We broadly classify opacity proxies into three categories. The first category of firm opacity measures is based on patterns of stock returns for individual firms. The proxies we test from this category include R-Square, Skewness and Crash probability. The second category of empirical firm-opacity proxies is based on the 
analysis provided by information intermediaries such as security analysts. Here we focus on number, dispersion, error and, revisions in analysts' forecast. The third set of opacity measures is grounded in market microstructure research. The intuition here is that opaque firms expose traders to a higher risk of being at the wrong end of an informed trade. Thus, shares of more opaque firms should be less liquid and more expensive to trade. The two microstructure proxies we focus on are the Amihud (2002) measure of price impact and the Hasbrouck (2009) measure of transaction costs. Below we discuss each of these categories in more detail.

We focus on nine empirical proxies from the three categories discussed above. All of these have been used as measures of information opacity of a firm. Researchers have used a wider set of measures than the one we test in this paper and it is worth highlighting the reason for our choice of these specific proxies. We are largely guided by two key questions faced by most researchers. The first question is how widely and easily available is the data that is required to construct the information opacity measure? The second question is how tractable is the computation of the proxy? All nine measures that we test are derived from three databases CRSP, COMPUSTAT and IBES - all of which are widely available to researchers. These databases have an additional advantage of covering a large universe of firms over a long period. The information opacity proxies we test are also relatively straightforward to compute. The methodology as well as computation procedures are readily available. Finally, we wanted to reflect the diverse motivations that have prompted previous researchers to choose different proxies. As discussed earlier, these proxies broadly reflect three different approaches of how information asymmetry may manifest itself in stock returns, coverage by informed agents, and market-microstructure.

The seminal papers that introduced some of these measures have been widely cited. For example, one of the early papers that uses R-square and skewness as measures of information asymmetry is Jin and Myers (2006). According to Web of Science (WOS) this paper has been cited over 170 times, of which 121 are in the 2010-2014 period. This paper is classified by WOS as a "Highly Cited Paper", defined as the "top one percent of its academic field based on a highly cited threshold for the field and publication year." The origins of modeling the relationship between a firm's transparency (informed trading volume) and liquidity is frequently attributed to Kyle (1985). A number of recent papers confirm the relationship between transparency and liquidity (e.g. Lang, Lins, and Maffet 2012). Liquidity itself can be measured in multiple ways and we chose the illiquidity measure proposed by Amihud (2002). This paper is also one of the most cited papers with over 700 citations in the 2010-2014 period according to WOS. One of the most appealing features of the Amihud measure is that it requires minimal availability of data for a firm. It can be estimated using only two types of data- the daily returns and the daily trade volume. Thus, this measure can be estimated for almost all firms with traded stock. Furthermore, 
as shown by Goyenko, Holden, and Trzcinka (2009), among different liquidity measures, the Amihud measure works particularly well despite being a low-frequency measure. When they estimate the correlation of various liquidity measure to a high frequency TAQ database measures such as 5-Minute Price Impact, they state “...For the 5-Minute Price Impact, Amihud has the highest correlation at 0.516 and is statistically significantly higher than any other measure ... ( $p$. 169)." This explains why a number of papers use Amihud's measure as a proxy for opacity in different contexts (see for example Flannery, Kwan, Nimalendran (2013) and Bharath, Pasquariello, $\mathrm{Wu}$ (2009)). While the Amihud measure captures the price impact of trading, some researchers focus on the effective/realized bid-ask spread as a proxy for firm opacity. The bid-ask spread captures the "cost" of trading a particular stock and a higher spread denotes a lack of transparency for that stock. However, the estimation of bid-ask spread requires use of high frequency TAQ data. Hasbrouck (2009) proposed an easy-to-compute measure based on low-frequency data that provides a robust estimate for the cost of trading of a security. According to WOS, this paper received over 100 citations (of which 81 are in the 2010-2014 period). This paper is also classified as a "Highly Cited Paper" by WOS. Based on its wide-spread usage, we include Hasbrouck's measure as one of the firm-opacity proxies in our tests. Finally, there are several papers that establish a link between analyst following and information production. These include Brennan and Subrahmanyam (1995), Roulstone (2003), and Yu (2008). Based on such a link, a number of previous studies employ analyst-based measures (analyst following, accuracy, dispersion, etc.) as proxies for transparency (see for example, Leary and Roberts (2010) and Flannery, Kwan, Nimalendran (2004)). Table A1 in the appendix lists some of these seminal papers and their citations count. To sum up, the measures we test reflect their wide-spread usage in finance and accounting research.

We describe the specific opacity measures that we test in this paper in more detail below. A concise description of all of the measures (as well as of the other relevant variables of our empirical analysis) is provided in Table I.

\section{A. Stock Return Based Measures}

\section{R-Square}

Stock prices can react to market-wide or company-specific information. ${ }^{6}$ French and Roll (1986) show that market-wide variation explains only part of the observed variation in returns of individual stocks. To estimate the extent of firm-specific factors in an individual firm's stock returns, researchers use the R-square from a regression model of individual stock returns. The basic approach in such tests is to run a time-series regression of contemporaneous stock returns

\footnotetext{
${ }^{6}$ See Roll (1988) for a detailed analysis of the relative importance of the two types of information.
} 
of an individual firm against well-established factors such as market, size and book to market (Fama-French 1993). The R-square from such a time-series regression of a multi-factor model captures the fraction of variability of that firm's stock return which can be explained by the common factors. Thus, an estimated R-square that is close to one implies that the stock behavior is largely influenced by market-wide factors rather than any company-specific information. Morck et al. (2000) find that the average R-square is higher in low-GDP countries relative to richer economies. They argue that the level of investor-protection in less developed countries is lower compared to that in higher GDP countries. They explain their findings of a higher R-Square in poorer economies in terms of a higher information opacity of firms listed in these countries. Sophisticated traders are less willing to bear the necessary cost to gather and analyze company-specific private information. This reluctance arises from the fear of not being able to recuperate this costly information gathering as poor investor protection laws make them vulnerable to insider trading. As a result, equity returns are less influenced by company-specific information and the R-square is higher. Jin and Myers (2006) build on Morck et al. (2000) and draw an important distinction between opacity and weak investors' protection. They show that poor protection is a necessary but not sufficient condition to explain a higher R-square. If investors can observe, but not oppose, cash flow extraction by insiders, we would see a reduction in stock prices (that will incorporate only the portion of outsiders' cash flow), but not a higher R-square because price changes will reflect all the information, both market-wide and firm-specific. Thus the authors conclude that opacity is essential to explain the higher stock price synchronicity. They predict that poor protection coupled with opacity leads to a higher R-square. Using several measures of opacity at the country-level, Jin and Myers (2006) show that more opaque countries exhibit higher average R-square.

Building on this literature, several papers have used the R-square as a proxy for opacity. For example, Durnev et al. (2003) find that firms and industries with a lower market model R-square exhibit a higher association between current returns and future earnings, indicating the greater degree of information about future earnings that is incorporated into current stock returns. Hutton et al. (2009) empirically investigate the effect of earnings manipulation on the market model R-square. They report that a high R-square is associated with greater earnings manipulation. Haggard et al. (2008) look at the effect of voluntary disclosure on stock price informativeness. They find that enhanced voluntary disclosure is associated with a lower R-square.

Taken together, the studies discussed above suggest that a higher R-square implies a higher level of firm opacity. However, this view has been challenged by a number of recent studies (Kelly (2014), Dasgupta, et al. (2010), and Chan et al. (2013)). These papers have argued the opposite-that a higher level of R-square is associated with greater transparency rather than opacity. The number of analysts who follow a particular company is frequently used as a measure 
of information that is available about a firm. This implies that the greater the number of analysts following a specific firm, the lower the firm-opacity for that firm. However, recent empirical papers have shown a significant positive relationship between the level of analyst coverage and the stock return synchronicity i.e. R-Square. ${ }^{7}$ Thus, the firms with high analyst coverage also tend to have a high R-square. To the extent that greater analyst coverage enhances firm transparency, the R-square would thus proxy for transparency rather than opacity. Kelly (2014) and Dasgupta et al. (2010) also provide evidence that a high level of a firm-level R-square appears to be associated with a more transparent information environment. Thus, the use of the R-square as a measure of opacity deserves a detailed empirical analysis.

We build our R-square opacity measure by running a standard Fama-French-Carhart four-factor model on weekly returns within the fiscal year of each listed company. This allows us to generate an R-Square value for each firm-year observation in our sample. To address the issue of thin trading of small capitalization stocks, we follow Dimson (1979) and also include one lead and one lagged observation for all of the independent variables. The R-Square is computed for the following OLS regression model:

$$
\begin{aligned}
& r_{i, t}= \\
& \alpha_{i, t}+\sum_{k=-1}^{+1} \beta_{1 i, k} M K T_{t+k}+\sum_{k=-1}^{+1} \beta_{2 i, k} S M B_{t+k}+ \\
& \sum_{k=-1}^{+1} \beta_{3 i, k} H M L_{t+k}+\quad \sum_{k=-1}^{+1} \beta_{4 i, k} U M D_{t+k}+\epsilon_{i, t}
\end{aligned}
$$

Where $r_{i, t}$ is the weekly excess return over the risk free return for stock $i$ in week $t . M K T_{t}$ denotes the weekly excess return over the risk free rate for week $t$. We use the CRSP value-weighted index to compute the market return. The terms $S M B_{t}, H M L_{t}$, and $U M D_{t}$ are the weekly returns for the size, value and momentum factors, respectively. ${ }^{8}$

The regression model described in equation 1 is estimated for each firm-year over that firm's fiscal year. To be included in the sample, we require that the firm-year must have at least 30 weekly return observations in a single fiscal year. These firm-year regressions yield a time series of R-square estimates corresponding to our panel of firm-year observations. The estimated R-square for any firm-year, by construction, is constrained to lie between zero and one. This makes its direct use problematic. Following Morck et al. (2000) we carry out a logistic transformation that allows the transformed variable to range from negative to positive infinity. This transformation is described below:

${ }^{7}$ See for example Hameed et al. (2010) and Chan and Hameed (2006).

${ }^{8}$ The weekly returns of the factors as well as the excess return of the market index and the risk free rate are obtained from Kenneth French's website. 


$$
\operatorname{Ln}\left(R^{2}\right)=\operatorname{Ln}\left(\frac{R^{2}}{1-R^{2}}\right)
$$

Thus, $\operatorname{Ln}\left(R^{2}\right)_{i}$ measures the synchronicity of stock returns of firm $i$ with that of market-wide factors.

\section{Return asymmetry}

An alternative measure of firm opacity can be obtained by looking at the asymmetry of equity returns. Weak investor protection allows firm insiders to expropriate shareholders, by capturing a fraction of the firm's cash flow. Jin and Myers (2006) show that when shareholders cannot observe part of the firm-specific factors affecting the cash flow generation (opacity), the optimal payout policy for the insiders is to distribute a fixed portion of the observable (to outsiders) cash flow. Therefore, when the hidden firm-specific information is positive (negative), insiders' capture will be higher (lower). In other words, insiders absorb firm-specific volatility, thus producing a higher R-square as a relatively smaller amount of firm-specific information gets incorporated into its stock price. However, insiders can only absorb a limited amount of unfavorable firm-specific information. If there is a sufficiently long run of adverse firm-specific news, insiders will exercise an abandonment option by releasing all of the accumulated negative information and thus generating an excessively sharp abnormal negative return. They define such events as a "crash". 9

Similar to the conflicting interpretation of the R-Square discussed earlier, previous studies of the relationship between return asymmetry and firm transparency are not unanimous in their interpretations. The empirical evidence in Hutton et al. (2009) supports the idea that a higher opacity is associated with a higher incidence of crashes, as they find that greater earnings management (their benchmark of "true" firm opacity) increases the likelihood of a stock price crash. However, Hong et al. (2000) find that stocks followed by a larger number of analysts (arguably less opaque firms) exhibit greater pronounced negative skewness (i.e. a higher tendency to crash). Moreover, Chen et al. (2001) find that firms with larger analyst following have higher negative skewness in their daily return distribution. Thus, the empirical findings on the use of "likelihood of crash" as a proxy for firm opacity is far from settled and merits further examination.

We describe the estimation procedure for this measure next. The regression model described in equation 1 allows us to generate a time series of weekly residual returns, $\epsilon_{i, t}$, for all the

\footnotetext{
${ }^{9}$ Kirschenheiter and Melumad (2002) provide an alternative theory that is also consistent with the positive relationship between opacity and crashes. They show that managers have an incentive to severely under-report earnings in response to particularly bad news, thus taking "big baths" in the current period in order to report higher earnings in the future. The idea is simple: The very act of large under-reporting makes the inferring of true earnings less precise i.e. making the firm more opaque. Since "big baths" are typically associated with a large drop in the stock price, firm opacity is positively related to a higher frequency of crashes.
} 
sample firm-year observations. We use these residuals to define crash risk. The residuals take into account price movements driven by market-wide fluctuations as well as the impact of other established factors (size, value and momentum). We use these residual returns to build two returns asymmetry-based opacity proxy variables. The first one is simply the skewness of the residuals distribution (SKEW). The lower the skewness, the higher is the relevance of large negative events. We follow Chen et al. (2001) and calculate the third moment of each stock's residual returns $\left(\epsilon_{i, t}\right)$ which we divide by the cubed standard deviation:

$$
S K E W_{i}=\mathrm{E}\left[\left(\frac{\epsilon_{i, t}-\mu\left(\epsilon_{i, t}\right)}{\sigma\left(\epsilon_{i, t}\right)}\right)^{3}\right]
$$

Thus for each firm-fiscal year, we estimate the $S K E W$ using the residuals from equation 1. Lower skewness implies a higher frequency of negative outliers. According to Jin and Myers (2006), lower values of SKEW will be associated with higher firm opacity.

The second measure of opacity based on return asymmetry that we construct is derived from the likelihood of experiencing significantly large return outliers. We define this measure as CRASH. Following Jin and Myers (2006), we calculate the difference between the number of "extremely low" and "extremely high" residual returns in the fiscal year. A return is considered "extreme" when it exceeds 3.09 standard deviations above or below the mean, with 3.09 chosen to generate a frequency of 0.1 percent in the normal distribution. In order to account for the log-normality of short term returns due to firm leverage (see Schwert, 1989) we apply a log-normal transformation, i.e. $\ln \left(1+\varepsilon_{i, t}\right)$, where $\varepsilon_{i, t}$ are the residuals of a standard Fama-French-Carhart four-factor model (equation 1) estimated over a year of weekly observations. ${ }^{10}$ We are interested in examining the occurrence of negative abnormal events rather than the simple kurtosis of the return distribution. Thus, following Jin and Myers (2006), we subtract the upside frequencies from the downside frequencies. Netting out the number of positive extreme occurrences from the number of negative extreme occurrences gives us a measure of the opportunistic behavior of insiders described above which is the main driver of firm level opacity.

\section{B. Analyst Based Measures}

Analysts play an important role in gathering and disseminating information about the firms that they follow (Womack, 1996; Brav and Lehavy, 2003; Barber, Lehav and Trueman, 2010). Analyst-based measures are commonly used in finance and accounting literature. The quantity

${ }^{10}$ Our results are unchanged when we use critical values of $1 \%$ and $0.01 \%$. 
and quality of analyst coverage has been frequently linked to firm opacity (Flannery et al., 2004 and Van Ness et al., 2001) or, similarly, to the speed of information disclosure (Hong et al., 2000). We employ three commonly used analyst-based measures of opacity which we describe below.

Quantity: The number of analysts who cover a certain company should be positively correlated to the quantity of available information. However, it is important to note that causality can run in both directions. On one hand, fewer analysts produce less information, thus resulting in a more opaque firm. On the other hand, one could argue that analysts are less interested in covering an opaque firm. In that case the causality runs from firm opacity to analyst coverage. Regardless of which direction the causality flows, it is safe to assume that a greater number of analysts should be correlated with lower firm opacity (e.g. Gomes and Phillips, 2012).

Dispersion: More opaque firms are harder to analyze and are expected to generate larger dispersion in the forecast of future performance. Thus, higher dispersion across the analysts who follow a particular company should be associated with higher opacity (e.g. Leary and Roberts, 2010).

Accuracy: Again, the more opaque a firm, the less reliable would be its consensus forecast, which in turn, is likely to generate larger discrepancies between the actual performance and the forecasted performance. Researchers have used the absolute size of forecast error as a measure of firm opacity (e.g. Bakke and Whited, 2010).

The work cited above suggests that the extent and quality of analyst coverage may be a good proxy for a firm's transparency. Nevertheless, these proxies also have some shortcomings. The argument for using analyst coverage-based measures to proxy for firm opacity is far from settled. While many papers suggest that analysts generate valuable information on the prices of stocks (e.g., Bradley 2013), recent studies have challenged this view. For example, Altinkilic and Hansen (2009) report that analyst activity conveys virtually no information. Also, Loh and Stulz (2011) focus on analyst recommendations that are released on days without firm-specific news and find that the majority of recommendations are uninformative. In our tests we find that analyst following appears to be related to firm opacity. However, we do not make any inference about the direction of causality. Thus, our findings are also consistent with an alternative explanation in which analysts do not produce any incremental information, but simply follow more transparent firms. ${ }^{11}$

Moreover, while forecast dispersion is generally associated with uncertainty (and hence opacity), it is also possible that more uncertainty may lead to herding among analysts (Jegadeesh and Kim, 2010). This would in turn result in lower dispersion. Similarly, if firms manage their

\footnotetext{
${ }^{11}$ However recent papers based on natural experiments suggest that analyst coverage has a material impact on stock prices (Kelly and Ljungqvist, 2012) as well as on corporate investment policies (Derrien and Kecskes, 2013).
} 
announced earnings to meet analyst expectations, an observed smaller forecast error is simply a manifestation of a higher degree of earnings management. It can be argued that the ability to manipulate earnings (to achieve lower forecast error) is more likely for an opaque firm than for a transparent firm. Thus, the relationship between analyst coverage and firm opacity is not straightforward.

In this paper, to proxy for firm opacity, we use four measures based on analyst forecasts which have been widely deployed by researchers. The first one is simply the number of analysts who cover a given company in a given year. We denote this measure as NUMEST. Since this number can change during the year as new analysts initiate coverage and existing analysts drop coverage, we take the number of analysts covering the firm six months from the end of the fiscal year.

The second measure is based on the dispersion of earnings forecast across all the analysts covering a particular firm. For each firm year we tabulate the fiscal year-end earnings forecast of all the analysts who cover that firm six months before the fiscal year end. We then calculate the standard deviation of these forecasts (across all the forecasts) and divide it by the closing price of the previous month. We denote this measure as DISP which is estimated as described below:

$$
D I S P_{i}=\frac{\sigma(E P S)_{i, t}}{P_{i, t-1}}
$$

where $\sigma(E P S)_{i, t}$ denotes the standard deviation of earnings per share forecasts of all the analysts and $P_{i, t-1}$ is the closing price of the stock for the prior month.

The next measure captures the accuracy (or lack thereof) of the forecasts made by the analysts. We calculate the absolute value of the difference between the mean earnings estimate $\left(\overline{E P S}_{i, t-6}\right)$ six months prior to the closing of the fiscal year for firm $i$ and the actual realized earnings per share $\left(\right.$ Actual $\left._{i, t}\right)$. Following Flannery et al. (2004), we divide this measure by the closing price of the previous month. We define this measure as ERROR which is estimated as described below.

$$
E R R O R_{i}=\frac{\mid \overline{E P S}_{i, t-6}-\text { Actual }_{i, t} \mid}{P_{i, t-1}}
$$

Our final opacity measure that is based on the quality and extent of analyst coverage is the REVISION RATIO. It is estimated by dividing the number of estimate revisions (both upward and downward revisions) by the total number of estimates available 6 months before the closing of 
the fiscal year. This measure captures the uncertainty faced by the analysts of a particular firm. As new information arrives about a firm, the analysts update their forecast to reflect this new information. Such revisions are likely to be less frequent for opaque firms as, by definition, there is less information available about them. On the other hand, the amount of information might be structurally lower for a given firm or industry, thus leading to a lower revision ratio, without necessarily implying greater opacity. For example, Flannery et al. (2004) use the revision ratio to proxy for firm opacity. They find that analysts post fewer revisions for NASDAQ-traded banks compared to comparable non-banking firms. However, since the mean forecast error and cross-section dispersion are lower for banks relative to non-banks, they conclude that a lower revision ratio simply reflects fewer changes in a bank's true value.

\section{Market-microstructure Based Measures}

Grossman and Stiglitz (1980) and Kyle (1985) provide a theoretical framework for how equity trading incorporates new information about a firm in its stock price. The intuition stems from the idea that more opaque firms expose investors to a higher risk of informed trading. When a firm is opaque, investors fear that they may be at the wrong end of a trade in which the counter-party has better information. As a consequence, less informed investors will be more reluctant to trade opaque assets. This, in turn, will reduce the liquidity of the stock.

In this paper, we use two measures of liquidity/cost of trading. Our primary selection criteria for these two measures is the ease of their computation from readily available data sources such as CRSP. Our first measure, AMIHUD, is the price impact measure developed by Amihud (2002) and is estimated from daily data on returns and volume. Goyenko et al. (2009) show that this simple and easy to implement measure fairs well compared to other price impact measures. It involves dividing the absolute daily stock return for a day by the dollar volume of total trading for that day. Thus, it captures the average impact on price per unit of trade. The intuition here is that a stock with a deep and liquid market will not move much per dollar of daily trading volume. Thus, this measure captures the price response to order flow. This ratio is estimated for each trading day during the fiscal year. The AMIHUD ratio for a firm-year is the average of these daily ratios. This is calculated as:

$$
\operatorname{AMIHUD}_{i}=\left(\frac{1}{D_{i}}\right) \sum_{t=1}^{D_{i}} \frac{\left|r_{i, t}\right|}{V O L_{i, t}}
$$

where $D_{i}$ is the number of valid observation days for stock $i$ during its fiscal year and $V O L_{i, t}$ is the dollar volume of stock $i$ on day $t$. Intuitively, this ratio measures the price impact of order flow, as a high value implies that for the same dollar amount of trading there is a larger 
change in price. Transparent firms are likely to have few traders that have an information advantage as the information is more widely disseminated. For the opaque firms, on the other hand, there is a greater likelihood that some of the traders have privileged information. Thus, such firms are likely to have a higher value of $A M I H U D$.

Our second measure of market microstructure-based opacity measure is HASBROUCK which is based on the methodology outlined by Hasbrouck (2009). Building on Roll (1984), Hasbrouck assumes that we cannot observe the true efficient price of a stock $\left(m_{t}\right)$, but only $\left(\log _{-}\right)$trade prices $\left(p_{t}\right)$. These, in turn, are the sum of the efficient price and the transaction costs $(c)$ :

$$
p_{t}=m_{t}+c q_{t}
$$

where $q_{t}$ is the unobserved trade direction indicator. The time dynamic of the efficient price can be represented as:

$$
m_{t}=m_{t-1}+\beta r_{M t}+u_{t}
$$

where $r_{M t}$ is the log return on the CRSP value-weighted market index, and $u_{t} \sim N\left(0, \sigma_{u}^{2}\right)$. The resulting trade price dynamic equation can be written as:

$$
\Delta p_{t}=c \Delta q_{t}+\beta r_{M t}+u_{t}
$$

The equation above can be estimated from daily prices over each fiscal year using the Bayesian inference via a Gibbs sampler on the joint distribution of $c, q_{t}$ and $u_{t}{ }^{12}$ We use the estimated transaction cost $c$ as our opacity proxy.

\section{Data and Sample Selection}

The two main databases that we use for our study are the CRSP/Compustat merged database and the IBES analyst forecast database. To construct our sample, we start with all firms in the Compustat/CRSP merged database for the 31-year period starting in 1981 and ending in 2011. The basic unit of analysis is firm-year and we include only those firm-years in which key accounting variables are not missing. This results in a sample of 180,925 firm-years. As we discussed earlier, a key set of tests in our paper focuses on examining the relative opacity of banking firms compared to non-banking firms. These tests are primarily aimed at testing the

\footnotetext{
12 The trading cost estimates have been calculated with the code available on Professor Hasbrouck's webpage.
} 
consistency of opacity proxies rather than settling the question of bank opacity. To create our banking and non-banking sub-samples, we follow Flannery et al. (2004) and classify all firms with SIC codes between 6021 and 6025, and between 6710 and 6712, as banks. This narrow definition reduces the size of the bank sub-sample but has the advantage of isolating a set of rather homogeneous companies in terms of business models. As described in Flannery et al. (2004), to construct the non-bank sub-sample, we drop all of the other financial firms such as insurance companies, brokerage firms (SIC codes 6000-6999), as well as regulated utilities (SIC codes 4800-4900). This reduces the sample to 152,461 firm-years. We also drop all firm-year observations if the market capitalization of a firm at the beginning of the year is less than $\$ 100$ Million (in 2005 constant dollars). Since we examine analyst-based measures of opacity we match the resulting sample with the IBES database and we retain only those firm-years in which at least one analyst EPS estimate is available. The requirement of having analyst coverage reduces the sample to 72,833 firm-years (5,183 bank firm-years and 67,650 non-bank firm-years) and 9,911 unique firms, which is our baseline sample for all the tests. The sample formation process is illustrated in Table II.

\section{Empirical Results}

\section{A. Are banks more opaque than non-banks?}

Commercial Banking (Depository Institutions) is one of the most heavily regulated industries. Few industries enjoy the level of explicit (deposit insurance) and implicit (too big to fail) government guarantees. It is natural to ask why banking is singled out for such treatment. Morgan (2002) provides one widely-held explanation based on the high level of opacity of banks: “...Banks are black boxes. Money goes in, money goes out, but the risks taken in the process of intermediation are hard to observe from outside the bank. Absent the steadying hand of government (deposit and payments insurance, lender of last resort, supervision and regulation of bank risk-taking) the opacity of banks exposes the entire financial system to bank runs, contagion, and other strains of "systemic" risk (p. 874)." However, the view of banks as relatively more opaque firms is not shared universally among scholars. Beston and Kaufman (1988) argue that banks may be easier to understand as a fair proportion of their assets trade in liquid markets and thus have a natural "mark-to-market" quality lacking in the assets of non-banking firms. Over the last decade mark-to-market accounting has been extended to ever larger classes of bank assets. Furthermore, many asset classes which used to be largely illiquid now have good secondary markets, making it easier to provide mark-to-market benchmarks. For example, a vibrant secondary market has developed for syndicated loans (Drucker and Puri, 2009), an asset class that was previously considered to be largely illiquid. Finally, both the US 
regulators as well as the guidelines from Basel banking supervision have attempted to increase the level of disclosure, which may have reduced bank opacity further.

In light of the discussion above, the relative opacity of banking institutions has become an interesting empirical question. However, since opacity cannot be measured directly, scholars have used firm characteristics that arguably stand in for the opacity of the assets owned by the firm. Morgan (2002) employs "disagreement" between two major bond-rating agencies (S\&P and Moody's) as a manifestation of inherent opacity of the firm. He argues “...if bank risk is harder to observe, the raters in the business of judging risk should disagree more often over bank bond issues ..." (p. 874). His key finding is that banks as a group have a significantly higher likelihood of having a "split rating" (i.e. S\&P and Moody's assign different ratings) at the time of a new issue of bonds. He argues that the greater disagreement is caused by the higher opacity of banks compared to other firms. Iannotta (2006) also employs split ratings and, using a sample of bonds issued by European firms in the 1993-2003 period, concludes that banks are more opaque than non-banks.

Flannery et al. (2004) take an alternative approach to measure opacity. They appeal to market microstructure literature to motivate the choice of their opacity measures and argue "...If banks are relatively difficult for outsiders to understand, the literature on equity market microstructure indicates that their shares should exhibit distinctive trading characteristics (p. 421)." They estimate a number of equity market structure characteristics for banks as well as for a set of matched non-bank firms. They fail to find any significant differences in the two groups and argue that banks are no more opaque than similar sized non-banks. As additional evidence, they also show that the dispersion and accuracy of analysts' forecasts for banks does not differ significantly when compared with such forecasts for non-banks. ${ }^{13}$

Thus, past studies on the question of bank opacity arrive at opposite conclusions. This conflict may partly be due to different opacity proxies employed as well as tests conducted over different sample periods. We address this issue by testing different opacity proxies over the same time period using the same sample and show how different proxies still provide conflicting results.

\section{Univariate Tests of Bank Opacity}

To examine whether banks are characterized by a different level of opacity, in Table III we report descriptive statistics for our opacity measures and test the differences between our two sub-samples (banks vs. non-banks). Although in this univariate analysis we do not control for the

${ }^{13}$ Flannery et al. (2013) re-evaluate the question of bank opacity on a much longer sample period of 1990-2009 (the original paper examined the 1990-97 period), which includes the financial crisis of 2008. Their results confirm that during normal times (i.e., non-stressed), banks are no more opaque than non-banks. However, during the 2007-09 financial crisis bank opacity increased dramatically. 
structural differences between the two samples, the results are interesting nonetheless. All of our measures, with the exception of ERROR, differ significantly (at the one percent level) between the banks and non-banks. However, the interpretation of these differences is difficult as they provide conflicting results. The mean R-square is almost two percentage points higher for the banks compared to non-banks. This difference is significant at the one percent level and is consistent with banks being more opaque than non-banks if a high R-square is assumed to proxy for high firm-opacity.

However, the two other opacity measures based on stock market returns provide opposite evidence. $S K E W$ is higher for banks implying that they are less opaque compared to non-banks. Similarly, the mean value of the CRASH measure for banks is negative. This implies that, on average, banks tend to experience large positive returns more frequently than large negative returns. Non-banks, on the other hand, have a positive mean value of $C R A S H$. Thus, non-banks are more likely to have negative extreme returns. The difference in the mean $C R A S H$ values across banks and non-banks is significant at the one percent level. Consistent with $S K E W$ results, a comparison of $C R A S H$ suggests that banks are less opaque.

Analysts-based measures indicate lower opacity of banks. On average, banks have one additional analyst compared to non-banks. Given that on average there are nine analysts for each firm-year, this difference translates into an almost 14\% higher analyst coverage for the banks. The difference of means is significant at the one percent level. Not only are banks covered by a larger number of analysts, the dispersion of earnings forecast $(D I S P)$ of bank analysts is lower compared to that of analysts covering the non-banks $(0.82 \%$ vs. $1.09 \%)$. Thus, the earnings forecast of bank analysts appear to have a tighter distribution. Also the difference between the consensus forecast and actual earnings $(E R R O R)$ is also lower than the difference in forecast versus actual for non-banks (albeit the difference is not significantly different from zero). Finally, the revision ratio for the non-banks is almost twice as high as that for the banks, implying a significantly higher incidence of earnings forecast revisions for non-banks. Taken together, all the analysts-based measures appear to support the results reported by Flannery et al. (2004), i.e. that banks are less opaque compared to non-banks. Also, unlike the stock return-based opacity measures, the analyst-based measures of opacity are internally consistent as all of them indicate that banks are less opaque compared to non-banks.

However, the results of market microstructure-based opacity measures are not as clear. The AMIHUD measure captures the impact of per dollar of trading volume on the price of a stock. Thus, a higher value of this measure suggests that the firm is more illiquid and thus more opaque. The AMIHUD measure for banks is almost twice as large compared to non-banks $(0.0206$ versus 0.0139). This difference is significant at the one percent level and implies that banks are less liquid and thus more opaque compared to non-banks. The HASBROUCK measure of trading 
costs, however, indicates that banks are less opaque as they have a significantly lower average trading cost ( 0.49 vs. 0.54$)$. As was the case for stock returns-based measures, the market microstructure measures also provide conflicting evidence on the relative opaqueness of banks.

While these univariate tests uncover interesting and conflicting patterns in the opacity of banks and non-banks, we should note that the two sub-samples may differ systematically along other firm characteristics. These characteristics, in turn, can influence the opacity measures that we have estimated. In Table 4 we report the results of our test that examines the similarity of our bank and non-bank sub-samples in terms of several relevant company characteristics. Our results show that the subsample of banks differs significantly when compared to non-banks. For example, an average bank in our sample is approximately 30\% larger (in terms of market capitalization) than an average non-bank (the difference is significant at the one percent level). Banks also have a significantly higher book to market ratio, a lower standard deviation of returns, and a lower share trading turnover. In order to control for these large and significant differences in two sub-samples we employ multivariate tests to ascertain if the opacity measures of banks continue to differ from those of non-banks once we control for other factors. These results are described next.

\section{Multivariate Tests of Bank Opacity}

To test if banks are indeed more opaque than non-banks, we estimate a regression model of the following form:

$$
(\text { OPACITY })_{i}=\alpha_{i}+(\text { BANK })_{i} \lambda+\mathbf{X}_{i} \beta+\sum(\text { YearDummies })_{t}+\varepsilon_{i}
$$

The dependent variable OPACITY is one of the nine opacity measures that we tested in Table III, such as the number of analysts, R-square, etc. The relevant independent variable in the model is $B A N K$, which is an indicator variable that takes the value one if the firm is a bank and zero otherwise. Thus, the key coefficient of interest is $\lambda$, or how does being a bank relate to the opacity measure being examined. In other words, if an increase in opacity measures is associated with a positive and significant estimate for $\lambda$, we can argue that banks as a group are more opaque compared to non-banks. The control variables are denoted by vector $\mathbf{X}$, which includes a number of firm-specific characteristics. Table 4 demonstrates that there are important differences in size, turnover, valuation ratios and other factors across the bank and non-bank sub-samples. 
Inclusion of these variables allows us to estimate more accurately whether banks are more opaque than non-banks. ${ }^{14}$

We report our results in Table $\mathrm{V}$, which provides the estimates over the 31-year sample period from 1981 to 2011 . In column 1 we report the results of estimating the regression model described in equation 10 in which we employ R-square (more precisely, the logistic transformation of R-square as described in equation 2) as the measure of OPACITY. The coefficient for $B A N K$ dummy is 0.143 which is significant at the one percent level. The positive and significant coefficient implies that the R-Square is significantly higher for a bank compared to a non-bank. Reversing the log-transformation, this coefficient translates into an increase of the R-Square of banks versus non-banks of roughly $8 \%$. The interpretation of R-Square used by Morck et al. (2000) and Jin and Myers (2006) suggests that banks are more opaque compared to non-banks. However, this result contradicts the findings we obtain when we employ other return-based measures as proxies for opacity. For example, in the regressions in which we use SKEW and CRASH as opacity measures (columns 2 and 3), the coefficients for BANK suggest that banks are less opaque compared to non-banks. The positive and significant coefficient on $B A N K$ when $S K E W$ is used as an opacity measure implies that banks have higher levels of skewness and thus are less likely to have extreme negative returns. Similarly, a negative and significant coefficient for $C R A S H$ implies that banks are less likely to see large negative stock price movement and are thus less opaque. ${ }^{15}$ Thus, even though R-Square, SKEW and CRASH are used by Jin and Myers (2006) as proxies of firm opacity, our results show that they yield conflicting results.

In column 4 we report the regression with the number of analysts following (more precisely, $\operatorname{Ln}(N U M E S T))$ as the dependent variable. The coefficient for BANK is -0.073 and it is significant at the one percent level, which can be interpreted as banks having fewer analysts compared to similar non-bank firms. If lower analyst coverage is associated with higher opacity, this result implies that banks are more opaque. The coefficient for $B A N K$ is positive for dispersion in

\footnotetext{
${ }^{14}$ The highly leveraged capital structure of banks makes them uniformly different from non-banks on this dimension. Given the high collinearity between leverage and BANK dummy we do not include leverage as an additional control variable. The use of BANK dummy also rules out implementing firm fixed effects.

15 The negative coefficient on CRASH for banks could also arise from implicit bail-out guarantees. We test for this by exploiting the widely-held belief that larger financial institutions are more likely to be seen as "Too Big To Fail" (TBTF) and are primary beneficiaries of such implicit bail-out guarantees. We divide our sample of banks into two groups based on their reported asset size. We create a dummy variable LRG_BANK which takes the value one if a bank reports assets greater than $\$ 100$ billion and zero otherwise. We create another dummy variable SML_BANK that equals one if the banks reports assets smaller than or equal to $\$ 100$ billion and zero otherwise. We re-estimate the Table $\mathrm{V}$ specification for the CRASH proxy in which the BANK variable is replaced by LRG_BANK and SML_BANK. We find that both the large and the small banks have similar coefficients for CRASH. The coefficient continues to be negative and significant at the one percent level for both types of banks. We interpret this result as implying that banks as a group, regardless of their size (i.e. implicit bail-out guarantees), are less prone to large negative share price movement compared to non-banks.
} 
analyst forecasts $(D I S P)$ but is not significant (column 5). In column 6 we report the estimation using the mean error in the analyst forecasts $(E R R O R)$ as a proxy for opacity. The coefficient for $B A N K$ is positive and significant at the one percent level. However, the final analyst-based proxy (REVISION RATIO) yields a negative and significant coefficient for BANK (column 7). Thus, two out of four analyst-based measures show higher bank opacity while one implies lower bank opacity and one is not significant.

In columns 8 and 9 we use the market microstructure-based measures of opacity. When we employ $A M I H U D$ as the opacity proxy, the coefficient for $B A N K$ is 0.008 and it is significant at the one percent level. Thus, banks appear to be less liquid and therefore more opaque. In column 9 we use $H A S B R O U C K$, the measure of trading costs, as our opacity proxy. Again the coefficient for $B A N K$ is positive and significant (at the five percent level), implying higher trading costs and thus higher opacity for the banks. We conduct additional robustness tests that are reported in the Internet Appendix to this paper. The overall results from these tests continue to show the inconsistencies across the different opacity proxies that we have described above.

In aggregate, the results reported in Table $\mathrm{V}$ and the additional robustness tests described in the Internet Appendix confirm the conflicting findings of previous studies of bank opacity. Our main contribution in Table $\mathrm{V}$ is to make transparent the important role of the choice of opacity proxy by the researcher. Of the nine opacity proxies that we employed, five provided statistically significant evidence that banks are more opaque than non-bank firms. Of the remaining four, three show that banks are significantly less opaque while one is not significantly significant.

To examine these discrepancies in more detail, we calculate pair-wise correlations across all of the opacity measures. We report the results of this analysis in Table VI. Overall, most of the pairwise correlations are significantly different from zero. Not surprisingly, we observe some correlations among measures that clearly capture similar phenomena: for example, $C R A S H$ and $S K E W$ are related to the asymmetry of the residual returns and are thus strongly correlated (correlation coefficient of -0.74). Similarly, two of the analyst-based measures, DISP and $E R R O R$, appear to be measuring similar characteristics as the correlation coefficient is 0.75 . Also, the two microstructure-based measures appear to be somewhat correlated among themselves (correlation coefficient of 0.37). Interestingly, if one takes a broader look across the different classes of opacity measures, one observes that the absolute level of correlations is fairly low. For example, most of the pairwise correlations that are greater than 0.20 are for measures within the three individual classes of opacity proxies. In contrast, most of the cross-family correlations are quite low, suggesting that different proxies may capture mutually exclusive firm characteristics. This in turn raises an interesting question: how can these low-correlated measures be considered sound proxy variables for the same unobserved quantity (firm opacity)? In the 
next section we try to address this apparent impasse and outline an empirical strategy to rank order these opacity measures.

We recognize that the results we report are subject to a joint hypothesis problem. We are simultaneously testing if a given opacity measure is indeed capturing opacity and whether banks are more opaque than non-banks. Our tests of relative opacity of the banks are not definitive given the joint hypothesis problem and are not the central contribution of this paper. Instead these results are meant to provide a first glance, superficial indication of the conflicting nature of existing opacity proxies. In the sections that follow we describe an identification strategy that allows us to examine how these opacity measures work across all industries rather than focusing on the narrow issue of bank opacity.

\section{B. Initiation of Credit Rating Coverage}

Our conflicting evidence on bank opacity suggests that the results are highly dependent on the proxy used. Thus, a test that ranks these information opacity proxies based on each proxy's ability to measure the information asymmetry should be helpful to scholars. A possible approach is to examine the change in various opacity proxies for a specific firm around an event that is an unambiguous and clearly identified shock (sometimes also referred to as "treatment") to the information environment of that firm. The basic insight is that such a shock/treatment will have a significant impact on the firm's opacity. If an opacity proxy is truly measuring the information asymmetry faced by the firm, that measure should also exhibit a considerable change in its level around the time of this shock.

We identify the "initiation of credit rating" as such a firm-specific event. The underlying assumption is that the first time assignment of a credit rating for a firm should unambiguously increase the level of that firm's transparency. The initiation of a credit rating for a firm indicates that an independent agent (the rating agency in this case) has collected and processed information about that firm, and released to the public an opinion about that firm's creditworthiness. Moreover, the decision to acquire a credit rating is usually associated with the future issuance of public debt. In that case, a new set of investors (potential bondholders) are interested in learning about the details of that firm's activities. It is plausible therefore, to assume that the rating initiation will be associated with greater transparency immediately following such an event. We want to highlight that we are not basing our test on the assumption that rated firms are more transparent than unrated firms. Rather, we are asserting that, on average, a formerly unrated firm will be more transparent following the publication of its rating.

We use the S\&P RatingsXpress database to collect information on the day a company is rated for the first time. We drop all rating initiations of financial and utilities companies, companies with a market value lower than $\$ 100$ million (constant 2005 dollars), and companies not covered 
in IBES. We are left with 1,202 events between 1981 and 2011. As a robustness check, we also use a wider definition of "rating initiation" in which we consider "true" initiations as well as rating updates after five years of rating inactivity (results unreported). The intuition of this second definition is that the information content of a rating can become "stale" and an update after a long period of inactivity can convey a similar amount of new information to the market. With this second definition the number of events increases to 1,853 .

After determining the rating date we measure the variation in our opacity proxies as the change between the average value of the measure in the 12 -month period from $t+7$ to $t+18$ and the average value in the 12-month period from $t-7$ to $t$-18 where $t$ is the month in which the rating is assigned. We skip the 6 months immediately before and after the rating assignation in order to allow our measures to react to the changes in the information environment. Since this calculation requires 18 months of available data before and after the rating, our sample of events is reduced by roughly one fifth when we estimate the different opacity proxies.

The decision made by a company to solicit a rating, as well as the decision of a rating agency to release an unsolicited rating, is not a random event. This complicates the causal inference about the effect of a rating initiation. Typically, firms solicit rating agencies when they plan to issue new bonds to finance new growth opportunities. The new bond issue can significantly alter the capital structure of the company. When companies solicit a rating they take into account the fact that some new information will be released to the general public in the form of an implicit estimate of their default probability. We can therefore expect newly rated companies to differ significantly from the general population over multiple dimensions. This makes it difficult to estimate the "treatment effect" of a rating initiation on the observed proxies of a firm's opacity. We address this issue by using the propensity score matching (PSM) methodology described below.

As shown by LaLonde (1986), non-experimental techniques such as multivariate regression can yield significantly biased estimates of the treatment effect. In statistics literature there is an established tradition of applying matching methods to address this causal inference problem. The propensity score matching (PSM) approach was originally developed by Rosenbaum and Rubin (1983, 1985) and subsequently extended by Heckman et al. (1997). This approach has become increasingly more common in recent finance literature (e.g. Michaely and Roberts, 2012).

We also employ the propensity score matching model in order to build a control sample of observations "similar" to the treated sample. Our sample is particularly well suited to this method as the pool from which we draw the control observations (i.e. firm-years) is quite large, which increases the probability of the overlap of observed firm-year covariates across the treatment and control groups. In other words, we are more likely to find "close" matches to firms that received a rating initiation among the group of firms that did not experience any rating status change. We 
model the decision of being rated with a probit model in which the dependent variable is set equal to one for the firm-month when a rating is assigned and zero otherwise. The independent variables capture firm characteristics that are likely to affect a firm's decision to seek a credit rating. Specifically, these include Ln(Size), Book-to-Price, profitability, turnover, stock volatility as well as the stock excess return over the market in the previous 12 months. Following previous research (e.g. Chen, 1991; Fama and French, 1989; Collin-Dufresne et al., 2001), we also add three time-related variables that capture the conditions of the primary bond market: short term interest rates, BAA-AAA credit spread and 12 month average CRSP value-weighted total market return. Finally, to capture industry-related factors we add the percentage of firms from the same industry that have an outstanding rating.

With this probit model we estimate the predicted value of the "propensity to be rated." The propensity scores are then used to match the firm-year of rating initiation with a control sample. As in Michaely and Roberts (2012), we perform this matching with replacement. Each treated observation is matched with the closest 5 (or closest 10) neighbors in terms of propensity score. Thus, for each firm-month observation of rating initiation, the matching procedure finds a set of 5 (or 10) observations that are statistically indistinguishable along multiple dimensions. The effectiveness of this matching process is described in Table VII, which presents a comparison of firm characteristics for the rating-initiation and control groups. Panel A provides the simple difference in means test between the treatment and the control sample of five closest matched observations along these characteristics and shows that the two are statistically indistinguishable in terms of size, profitability, market to book, leverage, past stock price performance and other macro-economic variables. Panel B describes the same tests using the ten closest matched firms as the control sample. Again, the profile of the control group is statistically indistinguishable from the treated group. As a final robustness check of our matching procedure we report the estimates from different probit regressions in panel C. As described earlier, we start our matching process by estimating a probit regression of an indicator variable that takes the value equal to one if the firm receives a credit rating for the first time and zero otherwise. In panel $\mathrm{C}$ we report the results from this first-stage probit estimation in the first column titled "Pre-Match." The probit results confirm that the initiation of rating is not random across firm-years and several firm and macroeconomic variables are significant. We extract the predicted probabilities (i.e. propensity scores) from the first-stage probit regressions and match each of the firm-month observations in which there was a rating initiation to corresponding firm-month observations that minimize the absolute difference between propensity scores. Thus we are able to generate a matching control "sample" for each of our "treatment" observations. We re-estimate the original probit specification but limit our sample to the treatment and control observations. These results are reported in the two columns titled "Post-Match". The results show that none of the coefficients 
are significant anymore and most of them experience a sharp decrease in magnitude as well. Thus, the results provided in the Post-Match columns illustrate that the matching procedure is successful.

Table VIII provides a detailed analysis of how the various firm-opacity proxies evolve in the pre- and post-rating initiation period for both the treated group (firm-year observations in which an actual rating initiation occurred) and the control or matched group (firm-year observations which were equally likely to get a rating initiation but did not). Out of our nine firm opacity proxies that we examine, only two (NUMEST and AMIHUD) consistently show a significant difference for the pre-rating and post-rating period. To illustrate this interpretation, let us focus on the first row of panel A. We see that while R-square increases both for the treated group (by $7.2 \%$ ) and the control group (by 9.9\%) the magnitude of change is statistically similar. We conduct a $t$-test for the difference between the two groups and we fail to reject the null hypothesis that the difference is equal to zero as the $t$-statistic is $-0.91 .^{16}$ The first empirical proxy for the firm opacity in which the difference in the two groups is significant is the number of analyst estimates (NUMEST). On average, firms that were rated for the first time have 1.15 more analysts following them in the post-rating period than in the pre-rating period. In contrast, the control group experiences an increase of only 0.44 analysts in the pre- and post-rating initiation period. The difference of 0.72 analysts is significant at the one percent level ( $t$-statistic of 4.99). This increase supports the argument that an increase in analyst following is a good proxy for a decrease in firm opacity.

The second measure to retain significance is the $A M I H U D$ illiquidity measure. This measure declines for the newly rated group but increases for the control group. The difference of -0.0081 reflects a lower impact on prices per unit of trading for the treated group. The difference is significant at the five percent level ( $t$-statistic of -2.05). Again, the rating initiation process is associated with a decrease in illiquidity (i.e. decrease in firm opacity).

Panel B of Table VIII reports essentially similar findings when we increase the control group to include the ten nearest matches to each treatment group observation. Finally, a third variable, Revision Ratio, shows a significantly greater increase for the firms that were rated. While the difference is statistically significant (at the five percent level) for the matched sample of the five

\footnotetext{
${ }^{16}$ We follow the methodology developed by Abadie and Imbens (2012) in estimating our models. In a series of papers Abadie and Imbens, $(2006,2011,2012)$ show that when matching is done on more than one continuous covariate, the standard matching estimators are biased, even in infinitely large samples. In our case this is not a critical issue since we only match on a single continuous variable - the propensity score. This advantage, however, comes at a price: the matching is being done on a variable that is estimated rather than directly observed. Abadie and Imbens (2012) show that first step estimation of the propensity score affects the large sample distribution of propensity score matching estimators, and derive adjustments to the large sample variance of propensity score matching estimators that correct for first step estimation of the propensity score. This is particularly relevant when estimating the effect of treatment on the treated, where ignoring the estimation error in the propensity score may lead to confidence intervals that are either too large or too small.
} 
nearest neighbors, it is not significant for the matched sample of the ten nearest neighbors. Given the lack of consistent significance and unexpected sign, we argue that the revision ratio does not appear to be a robust proxy for information opacity. We repeat these tests for the larger sample using a broader definition of rating initiation in which we also include any firm-year in which the firm receives a rating change following a period of at least five years of no rating action. To conserve space, we do not report those results. ${ }^{17}$ However, our main findings remain essentially unchanged. Of all the opacity proxies, only the NUMEST and the AMIHUD measure of illiquidity continue to show a significant and consistent difference in the newly-rated versus the control group.

It is worth highlighting that we are assuming a priori that a rating-initiation is always associated with a decrease in firm-opacity. This assumption seems fairly innocuous as we do not claim causality in either direction. The main role of a rating initiation event is to allow us to isolate those firm opacity proxies that show significant differences. Still, to examine the robustness of the analyst following and the AMIHUD illiquity measures, we conduct an additional set of tests which are described in the next section.

\section{Inclusion in the S\&P 500}

In order to test the robustness of our results we devise a second test based on another event that is likely to be associated with an increase of available information about a company. Specifically, we consider when a company is included as a constituent in the S\&P 500 Index. A number of studies have focused on additions (and deletions) to the S\&P500 Index constituent list. Scholars have posed two broad potential effects of such inclusions and exclusions. First, the announcement of being added to a prominent index leads to a significant change in institutional shareholding for that firm as many large index funds shift in (or out) of firms that are added (or deleted). This effect should translate into short term price pressures. The second effect is driven more by a change in information available about the firms that are added to the index. Unlike the short-term price pressures from portfolio adjustments, this effect is likely to create a longer lasting increase in price. A number of studies have confirmed the immediate price reaction to an announcement of being included in the index. ${ }^{18}$ Chen et al. (2004) show that the price increases following additions to the S\&P 500 Index are permanent. Elliott et al. (2008), in their analytical survey, conclude that the increased investor awareness (i.e. decrease in firm opacity) is the primary factor behind the cross-section of abnormal announcement returns. These studies suggest

\footnotetext{
17 These results are available from the authors on request.

18 See for example, Dhillon and Johnson (1991) for the pre-1989 period when the announcement and implementation used to take place on the same day. Since October 1989, Standard \& Poor has changed its policy and now announces the change one week prior to actual implementation. Lynch and Mendenhall (1997) document post-announcement positive returns that persist following the announcement for the post-1989 period.
} 
that there is a significant increase in information availability about the firm when it is first included in the S\&P 500 Index. We exploit this cleanly identifiable and discrete event to repeat our difference-in-difference test.

Again, we know that index inclusion is not random. However, Standard \& Poor's (2012) allows us to get an understanding of the selection criteria for an index inclusion decision. This facilitates our computation of a propensity score with a probit model that is reasonably specified. Specifically, S\&P considers a firm's market capitalization, liquidity, financial viability (past four quarters of earnings) and sector classification. We drop from the possible pool of control observations all firms that do not have four quarters of positive net income (excluding discontinued operations and extraordinary items). This exclusion reflects the fact that such firms would not be eligible for inclusion in the index according to the S\&P methodology. Our first stage probit model for estimating a propensity score includes firm-specific characteristics such as Ln(Size), Book-to-Price, ROE, Leverage, Turnover, Stock Volatility and profitability averaged over the previous four quarters. We also add industry fixed effects in order to obtain a control sample with the same industry composition as our treatment sample. Since firms may enter and exit the index multiple times during our experiment, we consider only those inclusions in which the firm had not been part of the S\&P 500 Index for the five years or more preceding the date of inclusion.

Table IX shows that the treatment and the control sample are comparable across all characteristics. For example, the average size as measured by the natural log of total assets is 8.04 for firms that are included in the S\&P 500 Index while the matched sample of firms (closest 5 matches) that are not part of the S\&P 500 has an average of 8.07 (Panel A, Table IX). The $t$-test of the difference between the two samples is -0.40 , which is statistically indistinguishable from zero. Thus the two samples are composed of statistically similarly sized firms. Comparing the differences across various operating ratios such as the Return on Equity (ROE), Book-to-Price $(\mathrm{B} / \mathrm{P})$ and Leverage yields similar results. The comparison of stock price characteristics such as monthly turnover and standard deviation also show that the two samples are well-matched. To save space we do not report results on the industry fixed effect but the two samples do not have any significant difference in terms of industry composition either. Panel B reports the results of matching ten closest neighbors to the sample of firms that were included in the S\&P 500 Index. The statistical similarity between the "treatment" and "control" sample again shows that the matching process is successful. Panel $\mathrm{C}$ reports the results from Pre-Match and Post-Match samples. The first column titled Pre-Match provides estimates of the first stage probit and shows that a number of firm-characteristics are significant predictors for index-inclusion. The same probit regression on the Post-Match sample shows that none of the coefficients are significant anymore. This provides additional evidence that the matching process is well specified. 
We report the results of our difference-in-difference tests in Table X. The results confirm the correct and significant reaction of NUMEST and the AMIHUD illiquidity measures. Similar to our results in Table VIII, the number of analysts goes up by 2.37 analysts in the post index inclusion period for the firms added to the S\&P 500 Index while it goes up by 1.23 analysts for the control sample of five closest matches (panel A). The difference of 1.14 analysts is significantly different from zero at the one percent level ( $t$-statistic of 5.12). The AMIHUD illiquidity measure goes down for the firms recently included in the index while it goes up for the control group. The net difference across the two groups is significant at the five percent level ( $t$-statistic of -2.19). Both of these measures continue to be significant when we increase the control sample to include the ten nearest matches (panel B). Apart from these two firm-opacity proxies, two additional stock return based measures ( $S K E W$ and $C R A S H$ ) for the treatment group are also significantly different from the control sample in the post-index inclusion period. However, the change in these proxies is the opposite of the predicted direction. If opacity is positively correlated to extreme negative events (low value of $S K E W$ and high value of $C R A S H$ ), and if the index inclusion signals a reduction in the firm-opacity, we should expect the inclusion in the index to be associated with a decrease in the frequency of extreme negative events, i.e. an increase in $S K E W$ and a decrease in $C R A S H$. However, the results of our tests show that after becoming constituents of the S\&P 500, companies experience a decrease of skewness and an increase in crash measure and these variations are significantly different from those in the control sample. These findings cast some doubt on the viability of using stock-return based proxies (R-square, SKEW and CRASH) to estimate firm-opacity.

\section{Robustness Tests}

Our difference-in-difference tests are based on observed changes in information opacity measures estimated six months before and six months after a treatment (index inclusion or rating initiation). We perform additional checks to see if the results hold when the "before" and "after" gap around the treatment is changed to a different period. We run the robustness tests with the "before" and "after" gap reduced to four months. We find that the only opacity measures that are significantly different when a firm initiates a rating are the NUMEST and AMIHUD which is similar to what we found in our original specification. The results are also similar when inclusion in the S\&P 500 is used as the treatment. When we reduce the "before" and "after" gap around the treatment to three months, the number of analyst estimates (NUMEST) is significantly different across all specifications. The AMIHUD measure is also significant in all specifications except in one (using the closest five neighbours for rating initiation). Again, no other proxy is consistently significant across all specifications. Thus, our difference-in-difference results are robust to different "gap" periods. Since these results are essentially unchanged from the results reported in 
Tables VIII and X, we do not report them in the paper but these are reported in the Internet Appendix.

We also conducted additional robustness tests for our propensity score matching methodology. We re-estimated our results for the rating initiation and the index inclusion using the nearest one neighbor match. In these estimates the number of analysts continues to be consistent and significant for both the rating initiation as well as the index inclusion. The Amihud measure is also consistent and significant for index inclusion but narrowly misses the conventional statistical threshold for rating initiation ( $p$-value of $12.5 \%$ ). We also estimated the same specification using a kernel-based matching approach. In this procedure each treatment observation is matched with a weighted average of all the control observations (within the common support region) where the weights are inversely proportional to the distance of their propensity score from that of the treated observation. We employed a Gaussian kernel in which the non-linear transformation is derived from the Gaussian density function. Again, the Amihud and the number of analyst estimates are the only proxies that provide consistent and significant results for both rating initiation as well as index inclusion. Finally, we tested the overlap condition to compare the densities of propensity score for the treatment and matched samples. The Kolmogorov-Smirnov test fails to reject the hypothesis of equality of densities for the treatment and matched samples for both rating initiation as well as for index inclusion. This provides additional evidence of a successful matching procedure. To conserve space, these additional robustness tests are not reported but are available in the Internet Appendix.

Our tests using the Propensity Score Matching (PSM) methodology show that the number of analysts (NUMEST) and the Amihud's illiquidity ratio (AMIHUD) are consistently better at capturing firm specific opacity. ${ }^{19}$ The main benefit of employing the PSM methodology is that it is free from bias arising out of an association between treatment status (i.e. inclusion in S\&P 500 index or initiation of rating) and "observable" firm variables. However, matching is still vulnerable to a "hidden bias" arising from a possible correlation between unobserved characteristics of a firm and that firm's assignment to the treatment group. The key issue we attempt to address is that the treatment is not assigned randomly to passive units. For example, firms choose to seek a bond rating rather than being assigned randomly to a group of issuers. This makes the treatment potentially endogenous.

DiPrete and Gangl (2004) and Gangl (2010) recommend using Instrument Variable (IV) estimation as an alternative to the PSM methodology. However, they also note that IV estimation imposes its own drawbacks such as a reduction in precision of estimates and a reliance on untestable assumptions. This approach of using both matching (PSM) as well as IV analysis is also adopted by Duchin and Sosuyra (2014). Our difference-in-difference tests for matched

\footnotetext{
${ }^{19}$ We thank the referee for suggesting alternative methodologies to test for robustness of our main results.
} 
samples suggested that the analyst following and the Amihud illiquidity measures were the only two consistent proxies that had the predicted sign and statistical significance when a firm was either included in the S\&P500 index or when it initiated the credit rating process. To examine the robustness of our results for these two proxies, we employ the instrument variable (IV) estimation. We construct instruments that are related to "New Constituent" and "Newly Rated."

For the inclusion in the S\&P 500 index (New Constituent), the instrument we use is SIZE_DIFF, which is constructed as the absolute value of the difference between the market value of every firm in the sample and the market value of the smallest constituent of the index. For every month this measure is estimated using the closing price at the previous month end. The results for this IV estimation are provided in the first three columns of Table XI. The first column reports the first-stage estimation. ${ }^{20}$ We include both the time and firm fixed effects. Every IV estimation needs to address the concerns about weak instruments. Stock and Watson (2006) state that "One way to check for weak instruments when there is single endogenous regressor is to compute the F-statistic testing the hypothesis that the coefficients on the instruments are all zero in the first stage regression... One simple rule of thumb is that you need not worry about weak instruments if the first-stage F-statistic exceeds $10 \mathrm{pp}$. (441)." The F-Statistic for our first stage is 105.06 suggesting that SIZE_DIFF is not a weak instrument. The coefficient for SIZE_DIFF is negative and significant at the one percent level providing strong evidence that SIZE_DIFF is a relevant instrument. Thus, for a particular firm, the larger the difference in its size compared to the smallest constituent, the less likely it is to be included in the index. Column 2 reports the results from second stage regression for analyst following. The coefficient for new constituent is positive and significant (at the one percent level) for analysts following suggesting that there is a significant increase in the number of analysts who follow a firm once it becomes part of the S\&P500. Column 3 reports the second stage estimation for Amihud illiquidity measure. The coefficient for new constituent is negative and significant at the one percent level implying that after inclusion in the S\&P 500 index, a firm's equity is more liquid.

In columns 4 through 6 we repeat the IV estimation for the initiation of credit rating. For the rating initiation we construct an instrument that we denote as FRAC_RATED. Each year we pool all Compustat firms in 17 Fama-French industry groups (available on Ken French's website).

\footnotetext{
20 As noted by the reviewer, modeling categorical dependent variables with fixed effects is econometrically challenging. Researchers have addressed this issue by using linear probability models instead of non-linear models. For example, Duchin and Sosuyra (2004) state “...Our choice of a linear rather than nonlinear model of loan approvals is motivated by two factors. First nonlinear models tend to produce biased estimates in panel datasets with a short time series and many fixed effects, leading to an incidental parameters problem and inconsistent estimates. Second, nonlinear fixed effects models generate biased estimates for interaction terms p.(9)., Iliev (2010) also employs the linear probability model for the first-stage regression. Brown et al. (2007) and Brickley and Dark (1987) discuss the merits of using linear versus non-linear models for categorical dependent variables and conclude that linear models provide consistent estimation of sign and significance both of which are our primary concerns for the first stage regression.
} 
FRAC_RATED is the ratio of the number of firms with credit rating in a particular industry to the total number of firms in that industry. Thus, a high FRAC_RATED value denotes that a large fraction of firms in that industry already have a rating. Firms choose if and when to seek a credit rating. A firm that does not have a rating while most other firms already have a credit rating, reflects an explicit choice made by that firm. If most of its industry-peers are already rated, the remaining unrated firms are likely to be those who have chosen not to seek rating. This can be interpreted as their revealed preference - they do not plan to issue public debt. This choice implies that such a firm is unlikely to seek a credit rating compared to a firm in an industry with few or no rated firms. The first-stage results in column 4 show a high $F$-Statistic of 179.18, addressing any concerns about our instrument being weak. Also the coefficient on FRAC_RATED is significant at the one percent level suggesting that our instrument is relevant. We report the second stage results for analyst following in column 5 . The coefficient for newly rated is positive and significant at the one percent level suggesting that analyst coverage increases after a firm obtains a credit rating for the first time. Column 6 reports the second-stage results for the Amihud illiquidity measure. The coefficient is negative implying higher liquidity in the post-rating period. However, the coefficient is not statistically significant. Taken together, these results imply that analyst coverage and (to a lesser extent) Amihud illiquidity measure are good proxies for firm opacity.

Thus, even after controlling for endogeneity, the shock to the information environment of a particular firm provides the predicted sign and significance for these two proxies. To ensure that the significance levels in our IV estimations are not driven primarily by our large sample size, we conduct a set of repeated estimations on randomly drawn smaller sub-samples using an approach described by Polotis and Romano (1994). We draw a subsample consisting of $10 \%$ of the total sample. The only constraint for the draw of this sub-sample is to respect the original proportion of treated and control firms in the original sample. We then conduct our Instrument Variables (IV) estimation on this smaller sub-sample and retain the coefficient estimate of our opacity proxy. We repeat this process of drawing a sub-sample followed by an IV estimation 200 times, and after each iteration we save the estimated coefficient of interest. This allows us to create a sample of 200 coefficient estimates and to observe their distributions. We conduct separate tests for "New Constituent" (of the S\&P 500 index) and "Newly Rated" (initiation of credit rating) respectively. For new constituent estimations all 200 coefficient estimates are positive for NUMEST and negative for AMIHUD. Both are significantly different from zero. For "Newly Rated" estimations we get qualitatively similar results. These provide further evidence that the number of analysts as well as the Amihud illiquidity measures are significantly related to the information opacity of a firm. These results are not reported but are available from the author(s) on request. 


\section{Conclusion}

In this paper we seek to classify and evaluate nine commonly used empirical measures of a firm's opacity. We classify these measures into three broad categories: i) Stock return-based measures, ii) Analyst-based measures, and, iii) Market microstructure-based measures. Our study is partly motivated by recent research on the relative opacity of banking firms versus non-bank firms. This research has yielded diametrically opposite results with some studies arguing that banks are less opaque while other scholars have provided evidence consistent with banks being more opaque. We investigate the question of bank opacity by using the different opacity proxies. Our first contribution is to show that the final results of bank opacity studies are extremely sensitive to the choice of opacity proxy being used. We show that different measures produce conflicting results in both univariate and multivariate tests. Our second contribution in this paper is to attempt a horse-race among these proxies to see which proxies best capture information opacity. To measure the effectiveness of various opacity proxies, we use credit rating initiation and inclusion in the S\&P 500 Index as two exogenous shocks to the firm information environment. We adopt a difference-in-difference approach by comparing newly rated firms with "unchanged" firms, i.e. already rated or unrated firms. The matched sample of control firms is created using the propensity score matching technique. Our results suggest that the number of analysts following and the price impact (as measured by the Amihud's (2002) ratio) show significant and theoretically consistent change when a firm is rated for the first time. We repeat this test using inclusion in the S\&P 500 index as the key information shock event. Again, the same two measures (number of analysts and Amihud illiquidity measure) show significant and consistent changes. Using the Instrument Variable (IV) estimation as an alternative approach we find similar results. To conclude, we test the nine commonly used empirical proxies for information opacity across different econometric specifications, different time periods and over randomly drawn sub-samples. We find that the number of analysts following a firm and the Amihud's measure of illiquidity are the only two measures that show a consistent and predicted relationship with a firm's opacity. For researchers interested in investigating the information environment of a firm, we recommend these two measures as the most robust and relevant proxies. 


\section{References}

Abadie A. and G.W. Imbens, 2006, Large sample properties of matching estimators for average treatment effects, Econometrica, 74(1), 235-267.

Abadie A. and G.W. Imbens, 2011, Bias-corrected matching estimators for average treatment effects, Journal of Business and Economic Statistics, 29(1),1-11.

Abadie A. and G.W. Imbens, 2012, A martingale representation for matching estimators, Journal of the American Statistical Association, 107(498), 833-843.

Altinkilic, O. and R. Hansen, 2009, On the information role of stock recommendation revisions, Journal of Accounting and Economics, 48(1), 17-36.

Amihud, Y., 2002, Illiquidity and stock returns: cross-section and time-series effects, Journal of Financial Markets, 5(1), 31-56.

Bakke, T. and T. Whited, 2010, Which Firms Follow the Market? An Analysis of Corporate Investment Decisions, Review of Financial Studies, 23(5), 1941-1980.

Barber, B. M., R. Lehavy, and B. Trueman, 2010, Ratings Changes, Ratings Levels, and the Predictive Value of Analysts' Recommendations, Financial Management, 39(2), 533-553

Benston, G. and G. Kaufman, 1988, Risk and solvency regulation of depository institutions: past policies and current options, Staff Memoranda 88-1, Federal Reserve Bank of Chicago.

Bharath, S., S. Dahiya, A. Saunders, and A. Srinivasan, 2011, Lending relationships and loan contract terms, Review of Financial Studies, 24 (4), 1141-1203.

Bharath, S., P. Pasquariello and G. Wu, 2009, Does asymmetric information drive capital structure decisions?, Review of Financial Studies, 22(8), 3211-3243.

Bradley, D., 2013 Bucking the Trend: The Informativeness of Analyst Contrarian Recommendations, Financial Management, 43(2), 391-414.

Brav, A. and Lehavy R., 2003. An empirical analysis of analysts' target prices: short-term informativeness and long-term dynamics, Journal of Finance 58(5), 1933-1968.

Brennan, M. and A. Subrahmanyam, 1995, Investment analysis and price formation in securities Markets, Journal of Financial Economics, 38, 361-81.

Brickley, J. and F. Dark, 1987, The Choice of Organizational Form The Case of Franchising, Journal of Financial Economics, 18(2), 401-420.

Brown, J., N. Liang and S. Weisbenner, 2007, Executive Financial Incentives and Payout Policy: Firm Responses to the 2003 Dividend Tax Cut, Journal of Finance, 62(4), 1935-1965.

Chan, K., A. Hameed, and W. Kang, 2013. Stock price synchronicity and liquidity. Journal of Financial Markets, 16(3), 414-438.

Chan, K. and A. Hameed, 2006, Stock price synchronicity and analyst coverage in emerging markets, Journal of Financial Economics, 80(1), 115-147.

Chen, N., 1991. Financial Investment Opportunities and the Macroeconomy, Journal of Finance, $46,529-554$.

Chen, H., G. Noronha, and V. Singal, 2004, The Price Response to S\&P 500 Index Additions and Deletions: Evidence of Asymmetry and a New Explanation, Journal of Finance, 41(4), pp.1901-1930. 
Chen, J., H. Hong, and J. Stein, 2000, Forecasting crashes: trading volume, past returns, and conditional skewness in stock prices in stock prices, Journal of Financial Economics, 61(3), 345-381.

Collin-Dufresne, P., R.S. Goldstein, and J.S. Martin, 2001, The determinants of credit spread changes, Journal of Finance, 56, 2177-2207.

Dasgupta, S., J. Gan, and N. Gao, 2010, Transparency, Price Informativeness, Stock Return Synchronicity: Theory and Evidence. Journal of Financial and Quantitative Analysis, 45(5) 1189-1220.

Derrien, F. and A. Keckés, 2013, The real effects of financial shocks: Evidence from Exogeneous Changes in Analyst Coverage, Journal of Finance, 68 (4), 1407-1440.

Dhillon, U. and H. Johnson, 1991, Changes in the Standard and Poor's 500 list, Journal of Business 85, 64-75.

DiPrete, T. A., and M. Gangl, 2004, Assessing bias in the estimation of causal effects: Rosenbaum bounds on matching estimators and instrumental variables estimation with imperfect instruments. Sociological Methodology, 34, 271-310.

Dimson, E., 1979, Risk Measurement when Shares are Subject to Infrequent Trading, Journal of Financial Economics, 7(2), 197-227.

Drucker S., and M. Puri, 2009, On loan sales, loan contracting, and lending relationships, Review of Financial Studies, 22(7), 2835-2872.

Duchin, R., and D. Sosyura, D., 2014, Safer ratios, riskier portfolios: Banks? response to government aid, Journal of Financial Economics, 113, 1-28.

Durnev, A., R. Morck, B. Yeung, and P. Zarowin, 2003, Does greater firm-specific return variation mean more or less informed stock pricing? Journal of Accounting Research, 41(5), 797-836.

Elliott, W. B., B. F. Van Ness, M. D. Walker, and R. S. Wan, 2006, What Drives the S\&P 500 Inclusion Effect? An Analytical Survey, Financial Management, 35(4), 31-48.

Fama, E.F. and K.R. French, 1989. Business conditions and expected returns on stocks and bonds. Journal of Financial Economics, 25, 23-49

Fama, E. and K.R. French, 1993. Common risk factors in the returns on stocks and bonds. Journal of Financial Economics, 33(1), 3-56

Faulkender, M. and M.A. Petersen, 2006. Does the source of capital affect capital structure? . Review of Financial Studies, 19(1), 45-79.

Flannery, M., S. Kwan, and M. Nimalendran, 2004, Market evidence on the opaqueness of banking firms' assets, Journal of Financial Economics, 71(3), 419-460.

Flannery, M., S. Kwan, and M. Nimalendran, 2013, The 2007-2009 financial crisis and bank opaqueness, Journal of Financial Intermediation, 22(1), 55-84.

French, K. and R. Roll, 1986, Stock return variances: The arrival of information and the reaction of traders, Journal of Financial Economics, 17(1), 5-26.

Gangl, M., 2010, Causal inference in sociological research, Annual Review of Sociology, 36, $21-47$. 
Gomes, A. and G. Phillips, 2012, Why do public firms issue private and public securities? Journal of Financial Intermediation, 21, 619-658

Goyenko, Ruslan Y., Craig W. Holden, and Charles A. Trzcinka, 2009, Do liquidity measures measure liquidity? Journal of Financial Economics, 92(2), 153-181.

Grossman, S. and J. Stiglitz, 1980, On the impossibility of informationally efficient markets, American Economic Review, 70(3), 393-408.

Haggard, K. S., X. Martin, and R. Pereira, 2008, Does voluntary disclosure improve stock price informativeness. Financial Management. 37(4), 747-768

Hameed, A., W. Kang, and S. Viswanathan, 2010, Stock market declines and liquidity, Journal of Finance, 65(1), 257-293.

Hasbrouck, J., 2009, Trading costs and returns for US equities: estimating effective costs from daily data, Journal of Finance, 64(3), 1445-1477.

Heckman, J. J., H. Ichimura, and P.E. Todd, 1997. Matching as an econometric evaluation estimator: Evidence from evaluating a job training programme, Review of Economic Studies, 64, 605-654.

Hong H., T. Lim, and J. Stein, 2000. Bad news travels slowly: size, analyst coverage, and the profitability of momentum strategies, Journal of Finance, 55(1), 265-295.

Hutton A., A. Marcus, and H. Tehranian, Opaque financial reports, R-square, and crash risk, Journal of Financial Economics, 94(1), 67-86.

Iannotta, G., 2006, Testing for opacity if the european banking industry: Evidence from bond credit ratings, Journal of Financial Services Research, 30(3), 287-309.

Iliev, P., 2010, The Effect of SOX Section 404: Costs, Earnings Quality, and Stock Prices, Journal of Finance, 65(3), 1163-1196.

Jegadeesh N. and W. Kim, 2010, Do analysts herd? An analysis of recommendations and market reactions, Review of Financial Studies, 23(2), 901-937.

Jin, L. and S. Myers, 2006, $\mathrm{R}^{2}$ around the world: new theory and new tests, Journal of Financial Economics, 79(2), 257-292.

Kelly, P. J., 2014, Information efficiency and firm-specific return variation, Quarterly Journal of Finance, 4(4), 1450018.

Kirschenheiter, M. and N. Melumad, 2002. Can "big bath" and earnings smoothing co-exist as equilibrium financial reporting strategies? Journal of Accounting Research, 40(3), 761-796.

Kyle, A., 1985, Continuous auctions and insider trading, Econometrica, 53(6), 1315-1335.

LaLonde R., 1986, Evaluating the econometric evaluations of training programs with experimental data, American Economic Review, 76(4), 604-620.

Lang, M., K. Lins and M. Maffett, 2012, Transparency, liquidity, and valuation: International evidence on when transparency matters most, Journal of Accounting Research, 50(3), 729774.

Leary, M. and M. Roberts, 2010, The pecking order, debt capacity, and information asymmetry, Journal of Financial Economics, 95(3), 332-355. 
Loh, R. and R. Stulz, 2011, When are analyst recommendation changes influential? Review of Financial Studies, 24(2), 593-627.

Lynch, A. and R. Mendenhall, 1997, New evidence on stock price effects associated with changes in the S\&P 500 index, Journal of Business, 70(3), 351-383.

Mehran, H., and S. Peristiani, 2010, Financial visibility and the decision to go private, Review of Financial Studies, 23(2), 519-547.

Michaely, R. and M. R. Roberts, 2012, Corporate dividend policies: lessons from private firms, Review of Financial Studies, 25(3), 711-746

Morck, R., B. Yeung, and W. Yu, 2000, The information content of stock markets: why do emerging markets have synchronous stock price movements? Journal of Financial Economics, 58(1), 215-260.

Morgan, D., 2002, Rating banks: Risk and uncertainty in an opaque industry, American Economic Review, 92(4), 874-888.

Myers, S., 1984, The capital structure puzzle, Journal of Finance, 39(3), 575-92.

Politis, D. N. and J. P. Romano, 1994, Large sample confidence regions based on subsamples under minimal assumptions, Annals of Statistics, 22, 2031-2050.

Roll, R., 1984, A simple implicit measure of the effective bid-ask spread in an efficient market, Journal of Finance, 39(4), 1127-1139.

Roll, R., 1988, R-squared, Journal of Finance, 43(2), 541-566.

Rosenbaum, P. and D.B. Rubin, 1983, The central role of the propensity score in observational studies for causal effects, Biometrika, 70, 41-55.

Rosenbaum, P. and D.B. Rubin, 1985, Constructing a control group using multivariate matched sampling methods that incorporate the propensity score, American Statistician 3, 33-38.

Roulstone, D., 2003, Analyst following and market liquidity, Contemporary Accounting Research, 20, 552-78.

Schwert, W., 1989, Why Does Stock Market Volatility Change over Time? , Journal of Finance, 44(5), 1115-1153.

Standard \& Poor's, 2012, S\&P U.S. indices methodology, March 2012 Edition, The McGraw-Hill Companies.

Stock, J.H. and M.W. Watson, 2006, Introduction to econometrics, Second Edition, Pearson

Sufi, A., 2007, Information asymmetry and financing arrangements: evidence from syndicated loans, Journal of Finance, 62(2), 629-668.

Van Ness, B. F.; R. A.Van Ness, and S. Richard, 2001, How Well Do Adverse Selection Components Measure Adverse Selection? Financial Management, 30 (3), 77-98.

Womack, K., 1996, Do brokerage analysts' recommendations have investment value? Journal of Finance, 51(1), 137-167.

Yu, F., 2008, Analyst coverage and earnings management, Journal of Financial Economics, 88, $245-71$. 


\section{Appendix}

\section{TABLE A1: Selection of Opacity Proxies}

This table reports the citation counts of seminal papers that employed the opacity proxies examined in our study. These are based on Web of Science (WOS) and Google Scholar. WOS defines a "Highly Cited Paper" as the "top 1\% of its academic field based on a highly cited threshold for the field and publication year."

\begin{tabular}{|c|c|c|c|c|c|}
\hline \multirow[t]{2}{*}{ Proxy Measure } & \multirow[t]{2}{*}{ Seminal Paper } & \multicolumn{3}{|c|}{ WOS citations } & \multirow{2}{*}{$\begin{array}{c}\text { Google Scholar } \\
\text { As of January } 2016\end{array}$} \\
\hline & & $\begin{array}{c}\text { As of January } \\
2016\end{array}$ & $2010-14$ & $\begin{array}{c}\text { Highly Cited } \\
\text { Paper }\end{array}$ & \\
\hline $\begin{array}{l}\mathrm{Ln}\left(\mathrm{R}^{2}\right) \\
\mathrm{SKEW} \\
\text { CRASH }\end{array}$ & Jin and Myers (2006) & 170 & 121 & Yes & 785 \\
\hline $\begin{array}{l}\text { NUMEST } \\
\text { DISP } \\
\text { ERROR } \\
\text { REVISION } \\
\end{array}$ & Brennan and Subrahmanyam (1995)* & 144 & 42 & No & 712 \\
\hline AMIHUD & Amihud (2002) & 864 & 710 & No & 4.42 \\
\hline HASBROUCK & Hasbrouck (2009) & 100 & 81 & Yes & 711 \\
\hline
\end{tabular}

*This is one of the first papers to introduce analyst-based measures as a proxy for opacity. Such measures are widely used in empirical corporate finance and banking (see for example, Leary and Roberts, 2010 and Flannery, Kwan, Nimalendran, 2004). 
Table I. Description of Key Variables

\begin{tabular}{|c|c|}
\hline \multicolumn{2}{|l|}{ Control Variables } \\
\hline Ln (Market value) & $\begin{array}{l}\text { (Natural Log of) Market Value at the end of the previous fiscal year. } \\
\text { Market Value = Common Shares Outstanding (Compustat Item \#25) x the Closing Price at the } \\
\text { end of the fiscal year (Compustat Item \#199). }\end{array}$ \\
\hline BANK & Equals 1 if the company SIC code is between 6021 and 6025 and between 6710 and 6712 . \\
\hline Return on Equity & Net income (Compustat Item \#172) $\div$ Common Shareholders Equity (Compustat Item \#60). \\
\hline Leverage & $\begin{array}{l}\text { Leverage is calculated as one minus the ratio between Common Shareholders Equity (Compustat } \\
\text { item \#60) and total assets (Compustat Annual Item \#6). }\end{array}$ \\
\hline Book to Price & $\begin{array}{l}\mathrm{B} / \mathrm{P} \text { is calculated as the ratio of book value of common equity }(\mathrm{B}) \text { to the market value of common } \\
\text { equity }(\mathrm{P}) . \mathrm{B} \text { is Compustat's common equity (Compustat item \#60) measured at the end of the } \\
\text { fiscal year. } \mathrm{P} \text { is the number of common shares outstanding (Compustat item \#25) multiplied by } \\
\text { the stock price at the end of the fiscal period (Compustat item \#199). }\end{array}$ \\
\hline St. Dev. & Is the standard deviation of weekly returns during the fiscal year. \\
\hline Turnover & Is the average turnover from CRSP monthly stock file averaged over the last 12 months. \\
\hline Equity Excess Return & $\begin{array}{l}\text { Is the difference between the average monthly return of the stock and the CRSP VW Total Market } \\
\text { index over the previous } 12 \text { months. }\end{array}$ \\
\hline Short Term Rates & $\begin{array}{l}\text { Is the beginning of month 3-Month Treasury Bill: Secondary Market Rate from the Board of } \\
\text { Governors of the Federal Reserve System. }\end{array}$ \\
\hline Credit Spread & $\begin{array}{l}\text { Is the beginning of month BAA - AAA Moody's Seasoned Corporate Bond Yields Spread from } \\
\text { the Board of Governors of the Federal Reserve System. }\end{array}$ \\
\hline Market Return & Is the average monthly return of the CRSP VW Total Market index over the previous 12 months. \\
\hline Percentage Rated & $\begin{array}{l}\text { Is the percentage of firms in a specific industry (Fama and French 48) with an outstanding credit } \\
\text { rating at the beginning of the month. }\end{array}$ \\
\hline \multicolumn{2}{|c|}{ Market Based Opacity Measures } \\
\hline $\operatorname{Ln}\left(\mathbf{R}^{2}\right)$ & $\begin{array}{l}\operatorname{Ln}\left(\frac{R^{2}}{1-R^{2}}\right) \text { where } \mathrm{R}^{2} \text { is computed by running a standard Fama-French-Charart four-factor model } \\
\text { on weekly returns within the fiscal year of each listed company as described in equation } 1 \text { in the } \\
\text { text. }\end{array}$ \\
\hline SKEW & $\begin{array}{l}\text { The Skewness is calculated as }\left(\frac{\epsilon_{i}-\mu\left(\epsilon_{i}\right)}{\sigma\left(\epsilon_{i}\right)}\right)^{3} \text { where } \epsilon_{i} \text { is the residual from a standard } \\
\text { Fama-French-Carhart four-factor regression model for firm } i \text { using weekly returns for each fiscal } \\
\text { year. } \sigma\left(\epsilon_{i}\right) \text { is the standard deviation of weekly } \epsilon_{i} \text {. }\end{array}$ \\
\hline CRASH & $\begin{array}{l}\text { Difference between the number of "extremely low" and "extremely high" residual returns in the } \\
\text { fiscal year. A return is considered extreme when it exceeds } k \text { standard deviations above or below } \\
\text { the mean, with } k \text { chosen to generate a frequency of } 0.1 \% \text { in the normal distribution. In order to } \\
\text { account for the log-normality of short term returns we apply a log-normal transformation } \\
\ln \left(1+\epsilon_{i}\right) \text { where } \epsilon_{i} \text { is the residual from a standard Fama-French-Carhart four-factor regression } \\
\text { model for firm } i \text { estimated over the firm's fiscal year using weekly returns. }\end{array}$ \\
\hline \multicolumn{2}{|c|}{ Analysts Based Opacity Measures } \\
\hline NUMEST & Number of earning estimates 6 months before the closing of the fiscal year. \\
\hline DISP & $\begin{array}{l}\text { Standard deviation of earning estimates } 6 \text { months before the closing of the fiscal year divided by } \\
\text { the closing price of the previous month. }\end{array}$ \\
\hline ERROR & $\begin{array}{l}\text { Absolute difference between the mean earning estimate } 6 \text { months before the closing of the fiscal } \\
\text { year and the realized earning divided by the closing price of the previous month. }\end{array}$ \\
\hline REVISION RATIO & $\begin{array}{l}\text { Number of earning revisions (up or down) divided by the number of estimates. Also this measure } \\
\text { is calculated } 6 \text { months before the closing of the fiscal year. }\end{array}$ \\
\hline \multicolumn{2}{|c|}{ Liquidity Based Opacity Measures } \\
\hline AMIHUD & $\begin{array}{l}\text { This is the illiquidity measure introduced by Amihud (2002). The measure is calculated as the } \\
\text { average (over the fiscal year) of the ratio between the absolute daily return and the daily dollar } \\
\text { volume. }\end{array}$ \\
\hline HASBROUCK & $\begin{array}{l}\text { This is the illiquidity measure introduced by Hasbrouck (2009). The measure is an estimate of the } \\
\text { effective transaction cost. }\end{array}$ \\
\hline
\end{tabular}




\section{Table II. Sample Selection}

The table below describes the sample selection for a study of firm opacity. The starting universe consists of all firm-years covered in Compustat for the 1981-2011 period. This set is narrowed down based on size and industry. We retain only those financial firms that can be classified as "Banks" as per definition followed in Flannery et.al. (2004). The firms classified as Banks are those with SIC codes between 6021 and 6025, and between 6710 and 6712 .

Compustat sample without missing values for key accounting variables 


\section{TABLE III. Univariate Tests of Opacity of Banks versus Non-banks}

This table reports the mean values and standard deviations for the opacity proxy variables described in Table I for a sample of banks and non-banks from 1981 to 2011. We define banks companies with a SIC code between 6012 and 6025 and between 6710 and 6712. The last two columns report the difference between the mean values for each firm characteristic for the bank and non-bank sample and the relative t-statistics for test of null hypothesis that the difference is insignificantly different from zero. $* * *, * *$ and $*$ indicate significance at the $1 \%, 5 \%$ and $10 \%$ respectively.

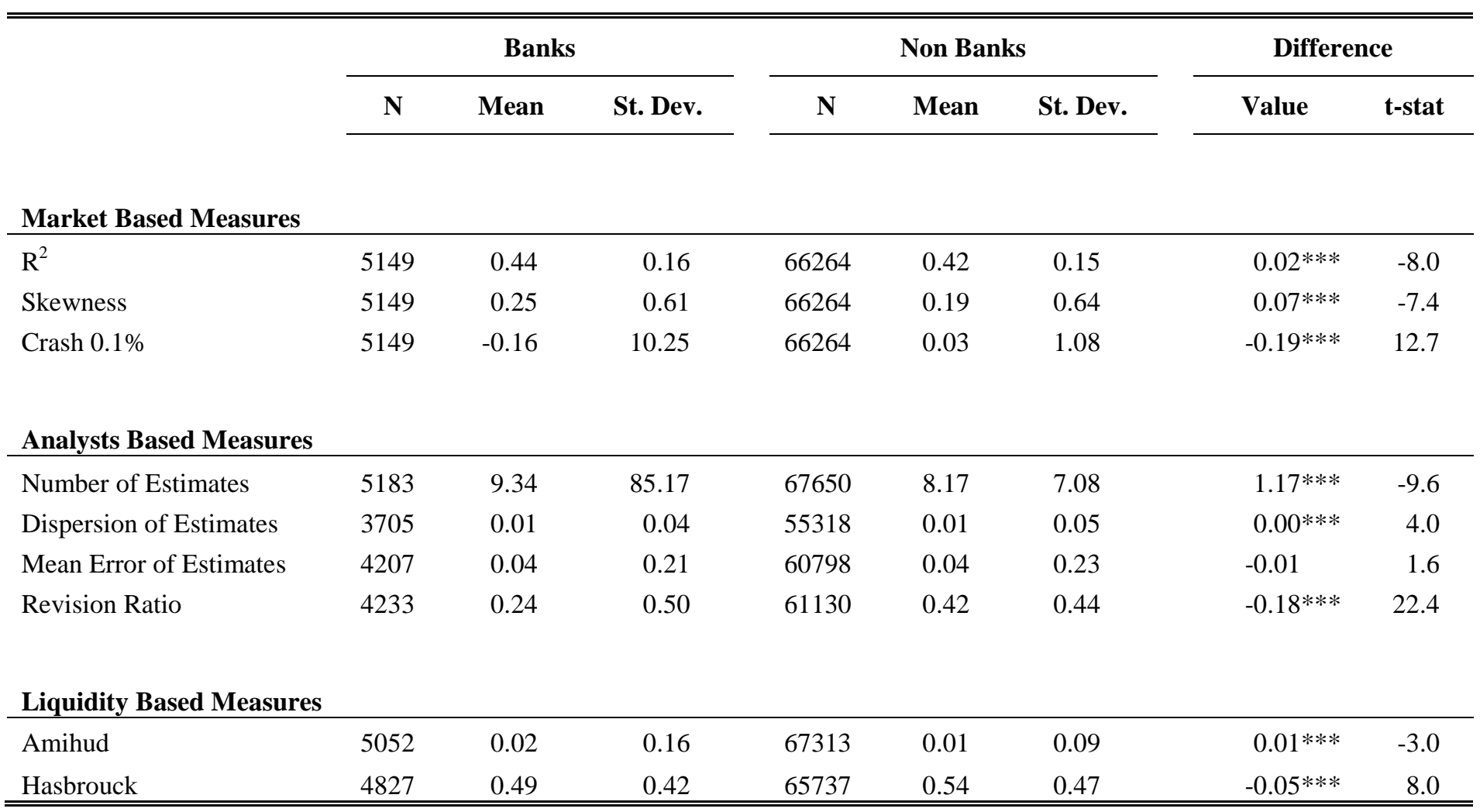




\section{TABLE IV. Firm Characteristics: Banks versus Non-Banks}

This table reports the sample means for firm characteristics for our two samples of banks and non-bank firms. The definition of how each variable is constructed is described in Table I. We define banks as companies with a SIC code between 6012 and 6025 and between 6710 and 6712. The last two columns report the difference between the ample averages across banks and non-banks and the t-statistics for the null hypothesis that this difference is zero. ***, ** and * indicate significance at the $1 \%, 5 \%$ and $10 \%$ respectively.

\begin{tabular}{lrrrr}
\hline \hline & Banks & Non Banks & \multicolumn{2}{c}{ Difference } \\
& & & \multicolumn{1}{c}{ Value } & t-statistic \\
\hline Number of Observations & \multicolumn{1}{c}{5183} & 67650 & \\
Market value (m\$) & 3660.90 & 2882.60 & $778.32^{* * *}$ & -3.39 \\
Book to Market & 0.83 & 0.58 & $0.25^{* * *}$ & -32.68 \\
Standard Deviation & 0.04 & 0.06 & $-0.02^{* * *}$ & 64.92 \\
Turnover & 0.64 & 1.55 & $-0.91 * * *$ & 58.76 \\
Excess Return & 0.02 & 0.01 & 0.00 & -0.79 \\
\hline \hline
\end{tabular}


TABLE V. Are Banks More Opaque than Non-Banks?

This table provides the OLS estimates of the following model.

$$
(O P A C I T Y)_{i t}=\alpha+(B A N K)_{i} \lambda+\mathbf{X}_{i t} \beta+\sum(\text { Year Dummies })_{t}+\epsilon_{i t}
$$

OPACITY is alternatively one of the nine different empirical proxies used to measure firm-opacity. Bank is dummy variable that equals one if the firm is classified as a bank and zero otherwise. We define banks companies with a SIC code between 6012 and 6025 and between 6710 and 6712 . Table I provides the detailed description of all other variables. All models also include time fixed effects. The t-statistics are reported in parentheses. $* * * * *$ and $*$ indicate significance at the $1 \%, 5 \%$ and $10 \%$ respectively.

\begin{tabular}{|c|c|c|c|c|c|c|c|c|c|}
\hline & (1) & (2) & (3) & (4) & (5) & (6) & (7) & (8) & (9) \\
\hline & $\operatorname{Ln}\left(\mathrm{R}^{2}\right)$ & SKEW & CRASH & Ln(NUMEST) & DISP & ERROR & $\begin{array}{c}\text { REVISION } \\
\text { RATIO }\end{array}$ & AMIHUD & HASBROUCK \\
\hline \multirow[t]{2}{*}{ Constant } & $-1.56 * * *$ & $0.19 * * *$ & $-0.21 * * *$ & $-1.21 * * *$ & $-0.01 * * *$ & $-0.06 * * *$ & $0.29 * * *$ & $0.04 * * *$ & $0.83 * * *$ \\
\hline & $(-72.93)$ & $(10.02)$ & $(-7.06)$ & $(-31.02)$ & $(-4.88)$ & $(-5.11)$ & $(18.23)$ & $(5.64)$ & $(48.57)$ \\
\hline \multirow[t]{2}{*}{ Bank } & $0.14 * * *$ & $0.11 * * *$ & $-0.15 * * *$ & $-0.07 * * *$ & 0.00 & $0.01 * *$ & $-0.13 * * *$ & $0.01 * * *$ & $0.02 * *$ \\
\hline & $(11.30)$ & $(10.71)$ & $(-9.21)$ & $(-3.01)$ & $(1.14)$ & $(2.38)$ & $(-12.55)$ & $(2.79)$ & $(2.17)$ \\
\hline \multirow[t]{2}{*}{ Ln(Market Value) } & $0.16^{* * *}$ & $-0.03 * * *$ & $0.03 * * *$ & $0.45^{* * *}$ & $0.00 * * *$ & $-0.00 * * *$ & $0.01 * * *$ & $-0.01 * * *$ & $-0.09 * * *$ \\
\hline & $(58.65)$ & $(-12.88)$ & $(8.36)$ & $(86.71)$ & $(-3.53)$ & $(-3.18)$ & $(5.34)$ & $(-12.80)$ & $(-43.77)$ \\
\hline \multirow[t]{2}{*}{ Book to Price } & 0.01 & $-0.02 * * *$ & $0.03 * *$ & $0.02 * *$ & $0.01 * * *$ & $0.05 * * *$ & $0.03 * * *$ & $0.01 * *$ & $0.01 *$ \\
\hline & $(0.82)$ & $(-3.49)$ & $(2.37)$ & $(2.01)$ & $(7.29)$ & $(7.47)$ & $(3.69)$ & $(2.54)$ & $(1.95)$ \\
\hline \multirow[t]{2}{*}{ Turnover } & $0.00 *$ & $-0.03 * * *$ & $0.04 * * *$ & $0.08 * * *$ & $-0.00 * * *$ & $-0.00 * * *$ & $0.02 * * *$ & $-0.00 * * *$ & $-0.02 * * *$ \\
\hline & $(1.71)$ & $(-8.78)$ & $(8.14)$ & $(8.98)$ & $(-4.09)$ & $(-3.59)$ & $(6.60)$ & $(-5.74)$ & $(-8.63)$ \\
\hline \multirow[t]{2}{*}{ Std. Deviation } & $2.39 * * *$ & $3.66 * * *$ & -0.05 & -0.06 & $0.36 * * *$ & $1.52 * * *$ & $0.44 * * *$ & $0.19 * * *$ & $4.03 * * *$ \\
\hline & (18.46) & $(22.65)$ & $(-0.24)$ & $(-0.21)$ & (17.47) & (15.94) & $(4.54)$ & $(2.77)$ & (38.57) \\
\hline \multirow[t]{2}{*}{ Excess Return } & $0.10 * * *$ & $0.22 * * *$ & $-0.30 * * *$ & $0.08 * * *$ & $-0.01 * * *$ & $-0.03 * * *$ & 0.01 & $-0.01 * * *$ & $-0.07 * * *$ \\
\hline & $(16.10)$ & $(26.75)$ & $(-24.46)$ & $(11.02)$ & $(-11.76)$ & $(-11.46)$ & $(1.35)$ & $(-11.17)$ & $(-16.09)$ \\
\hline $\mathrm{N}$ & 66903 & 66903 & 66903 & 66903 & 56125 & 61071 & 61275 & 66903 & 65371 \\
\hline Adj. $R^{2}$ & 0.34 & 0.07 & 0.03 & 0.53 & 0.08 & 0.07 & 0.13 & 0.03 & 0.34 \\
\hline
\end{tabular}


TABLE VI. Correlation between Different Opacity Proxy Variables

The table below reports the pairwise correlation between different opacity proxy measures. Each cell reports two numbers - the top number is the pearson correlation coefficient. The second number reported in the parentheses is the t-statistic for the null hypothesis that the pairwise correlation coefficient reported in each cell is zero.

\begin{tabular}{|c|c|c|c|c|c|c|c|c|c|}
\hline & $\operatorname{Ln}(\mathrm{R} 2)$ & SKEW & CRASH & Ln(NUMEST) & DISP & ERROR & $\begin{array}{c}\text { REVISION } \\
\text { RATIO }\end{array}$ & AMIHUD & HASBROUCK \\
\hline $\operatorname{Ln}(\mathrm{R} 2)$ & 1 & & & & & & & & \\
\hline SKEW & $\begin{array}{c}-0.07 \\
(-19.75)\end{array}$ & 1 & & & & & & & \\
\hline CRASH & $\begin{array}{r}0.00 \\
-1.26\end{array}$ & $\begin{array}{c}-0.73 \\
(-286.35)\end{array}$ & 1 & & & & & & \\
\hline Ln(NUMEST) & $\begin{array}{r}0.22 \\
-60.81\end{array}$ & $\begin{array}{c}-0.10 \\
(-26.64)\end{array}$ & $\begin{array}{r}0.04 \\
-10.64\end{array}$ & 1 & & & & & \\
\hline DISP & $\begin{array}{c}-0.06 \\
(-13.38)\end{array}$ & $\begin{array}{r}0.04 \\
-10.77\end{array}$ & $\begin{array}{r}0.00 \\
-0.51\end{array}$ & $\begin{array}{c}-0.08 \\
(-19.55)\end{array}$ & 1 & & & & \\
\hline ERROR & $\begin{array}{c}-0.05 \\
(-11.75)\end{array}$ & $\begin{array}{r}0.03 \\
-6.59\end{array}$ & $\begin{array}{r}0.01 \\
-3.00\end{array}$ & $\begin{array}{c}-0.08 \\
(-21.08)\end{array}$ & $\begin{array}{r}0.75 \\
-273.19\end{array}$ & 1 & & & \\
\hline REVISION RATIO & $\begin{array}{r}0.12 \\
-30.88\end{array}$ & $\begin{array}{c}-0.02 \\
(-5.97)\end{array}$ & $\begin{array}{r}0.03 \\
-7.41\end{array}$ & $\begin{array}{r}0.00 \\
-0.28\end{array}$ & $\begin{array}{l}-0.01 \\
(-3.13)\end{array}$ & $\begin{array}{c}-0.02 \\
(-5.02)\end{array}$ & 1 & & \\
\hline AMIHUD & $\begin{array}{c}-0.08 \\
(-21.46)\end{array}$ & $\begin{array}{r}0.02 \\
-6.53\end{array}$ & $\begin{array}{c}-0.01 \\
(-2.45)\end{array}$ & $\begin{array}{c}-0.11 \\
(-30.57)\end{array}$ & $\begin{array}{r}0.07 \\
-16.75\end{array}$ & $\begin{array}{r}0.05 \\
-13.87\end{array}$ & $\begin{array}{l}-0.04 \\
(-9.80)\end{array}$ & 1 & \\
\hline HASBROUCK & $\begin{array}{c}-0.19 \\
(-50.93)\end{array}$ & $\begin{array}{r}0.09 \\
-23.22\end{array}$ & $\begin{array}{c}-0.03 \\
(-7.32)\end{array}$ & $\begin{array}{c}-0.31 \\
(-86.34)\end{array}$ & $\begin{array}{r}0.19 \\
-46.85\end{array}$ & $\begin{array}{r}0.16 \\
-41.90\end{array}$ & $\begin{array}{c}-0.10 \\
(-25.62)\end{array}$ & $\begin{array}{r}0.37 \\
-105.62\end{array}$ & 1 \\
\hline
\end{tabular}


TABLE VII. Propensity Score Matching Diagnostics: Newly Rated versus Control Sample

The panels A and B of this table report mean values for two samples; Treatment and Control. The treatment sample consists of those firm-years in which the firms received a S\&P credit rating for the first time. The control sample consists of firms that did not receive a rating and is constructed using the propensity score matching methodology based on first passage probit model with the explanatory variables provided below. Each observation in the treatment sample is matched with the closet 5 (panel A) or closest 10 (panel B) firms according to the propensity score. The last three columns report the difference in the mean values of key firm characteristics between the treatment and the control sample as well as the t-statistic and corresponding p-value. Panel $\mathrm{C}$ presents the coefficient estimates from different probit regressions of an indicator variable equal to one if the firm receives a rating for the first time (Treatment). The column titled Pre-Match specification (first column) is estimated on the entire sample. Based on the predicted probabilities (propensity score) from this first column probit, a "matched" control sample is constructed using the propensity score matching methodology. The columns titled Post-Match report results from a probit regression that has the same specification as the first column but is estimated on a sample that only consists of the treatment and matched firms. The variables are described in Table I. ***, ** and * indicate significance at the $1 \%, 5 \%$ and $10 \%$ respectively.

\begin{tabular}{lccccc}
\hline \hline \multicolumn{7}{c}{ Variable } & Panel A: Closest 5 neighbors & & & \\
\hline B/P Ratio & Treatment Sample & Control Sample & Difference & t-statistic & p-Value \\
ROE & 0.77 & 0.75 & 0.02 & 0.26 & 0.80 \\
Leverage & 0.02 & 0.01 & 0.00 & 0.54 & 0.59 \\
Size & 0.55 & 0.55 & -0.00 & -0.16 & 0.88 \\
Standard Deviation & 6.80 & 6.79 & 0.00 & 0.01 & 0.99 \\
Turnover & 0.03 & 0.03 & -0.00 & -1.08 & 0.28 \\
Equity Excess Return & 1.56 & 1.64 & -0.07 & -0.92 & 0.36 \\
Short Term Rates & 0.14 & 0.16 & -0.02 & -0.70 & 0.48 \\
Credit Spread & 4.74 & 4.64 & 0.09 & 0.83 & 0.41 \\
Market Return & 0.91 & 0.92 & -0.01 & -0.56 & 0.58 \\
Percentage of Rated & 0.16 & 0.16 & 0.01 & 0.68 & 0.49 \\
\hline
\end{tabular}

Panel B: Closest 10 neighbors

\begin{tabular}{lccccc}
\hline \multicolumn{1}{c}{ Variable } & Treatment Sample & Control Sample & Difference & t-statistic & p-Value \\
\hline B/P Ratio & 0.77 & 0.76 & 0.01 & 0.09 & 0.93 \\
ROE & 0.02 & 0.01 & 0.00 & 0.37 & 0.71 \\
Leverage & 0.55 & 0.55 & -0.00 & -0.04 & 0.96 \\
Size & 6.80 & 6.79 & 0.01 & 0.11 & 0.91 \\
Standard Deviation & 0.03 & 0.03 & -0.00 & -1.22 & 0.22 \\
Turnover & 1.56 & 1.63 & -0.07 & -0.91 & 0.36 \\
Equity Excess Return & 0.14 & 0.16 & -0.02 & -0.78 & 0.44 \\
Short Term Rates & 4.74 & 4.67 & 0.06 & 0.58 & 0.56 \\
Credit Spread & 0.91 & 0.93 & -0.01 & -0.76 & 0.45 \\
Market Return & 0.16 & 0.15 & 0.01 & 0.71 & 0.48 \\
Percentage of Rated & 0.38 & 0.38 & 0.00 & 0.28 & 0.78 \\
\hline \hline
\end{tabular}




\begin{tabular}{|c|c|c|c|}
\hline \multicolumn{4}{|c|}{ Panel C: Propensity Score Matching Diagnostics } \\
\hline & Pre Match & $\begin{array}{c}\text { Post-Match } \\
\text { (Closest } 5 \text { Neighbors) }\end{array}$ & $\begin{array}{c}\text { Post-Match } \\
\text { (Closest } 10 \text { Neighbors) }\end{array}$ \\
\hline Constant & $\begin{array}{l}-3.10 * * * \\
(-38.27)\end{array}$ & $\begin{array}{l}-0.93 * * * \\
(-5.76)\end{array}$ & $\begin{array}{l}-1.27 * * * \\
(-9.11)\end{array}$ \\
\hline B/P Ratio & $\begin{array}{c}0.00 \\
(0.14)\end{array}$ & $\begin{array}{c}0.00 \\
(0.34)\end{array}$ & $\begin{array}{c}0.00 \\
(0.15)\end{array}$ \\
\hline ROE & $\begin{array}{l}-0.03 \\
(-0.39)\end{array}$ & $\begin{array}{c}0.04 \\
(0.25)\end{array}$ & $\begin{array}{c}0.00 \\
(0.00)\end{array}$ \\
\hline Leverage & $\begin{array}{l}0.24 * * * \\
(4.48)\end{array}$ & $\begin{array}{l}-0.06 \\
(-0.57)\end{array}$ & $\begin{array}{l}-0.04 \\
(-0.45)\end{array}$ \\
\hline Size & $\begin{array}{c}0.00 \\
(0.15)\end{array}$ & $\begin{array}{c}0.00 \\
(0.04)\end{array}$ & $\begin{array}{c}0.00 \\
(0.10)\end{array}$ \\
\hline Standard Deviation & $\begin{array}{l}2.34 * * * \\
(3.61)\end{array}$ & $\begin{array}{l}-0.95 \\
(-0.77)\end{array}$ & $\begin{array}{l}-1.07 \\
(-0.99)\end{array}$ \\
\hline Turnover & $\begin{array}{l}0.03 * * * \\
(3.68)\end{array}$ & $\begin{array}{l}-0.01 \\
(-0.42)\end{array}$ & $\begin{array}{l}-0.01 \\
(-0.43)\end{array}$ \\
\hline Equity Excess Return & $\begin{array}{l}0.10 * * * \\
(5.65)\end{array}$ & $\begin{array}{l}-0.02 \\
(-0.59)\end{array}$ & $\begin{array}{l}-0.02 \\
(-0.59)\end{array}$ \\
\hline Short Term Rates & $\begin{array}{l}0.03 * * * \\
(5.70)\end{array}$ & $\begin{array}{c}0.01 \\
(0.99)\end{array}$ & $\begin{array}{c}0.01 \\
(0.70)\end{array}$ \\
\hline Credit Spread & $\begin{array}{l}-0.28 * * * \\
(-8.77)\end{array}$ & $\begin{array}{l}-0.05 \\
(-0.86)\end{array}$ & $\begin{array}{l}-0.06 \\
(-1.15)\end{array}$ \\
\hline Market Return & $\begin{array}{l}0.24 * * * \\
(3.61)\end{array}$ & $\begin{array}{c}0.04 \\
(0.30)\end{array}$ & $\begin{array}{c}0.04 \\
(0.33)\end{array}$ \\
\hline Percentage of Rated & $\begin{array}{c}0.13^{*} \\
(1.75)\end{array}$ & $\begin{array}{c}0.06 \\
(0.44)\end{array}$ & $\begin{array}{c}0.03 \\
(0.25)\end{array}$ \\
\hline Treated & 942 & 942 & 942 \\
\hline Control & 552881 & 4710 & 9420 \\
\hline Control (Unique Obs.) & 552881 & 4687 & 9327 \\
\hline pseudo $\mathrm{R}^{2}$ & 0.02 & 0.00 & 0.00 \\
\hline
\end{tabular}




\section{TABLE VIII. Difference-in-Difference Analysis of Rating Initiation}

This table reports the results of a difference-in-difference (DID) analysis of the nine opacity proxy variables described in Table I for two samples: The treatment sample consists of those firms that received a rating for the first time and control sample which consists of firms that were as likely (based on propensity score matching) to get such a rating but did not receive it. The creation of control sample is constructed using the propensity score matching methodology based on first passage probit model with the explanatory variables detailed in Table VII. Each observation in the treatment sample is matched with the closest 5 neighbors (panel A) or the closest 10 neighbors (panel B) according to the propensity score. For each measure we first calculate the difference between pre- and post-rating values across the treatment group by subtracting the pre-rating value from the post-rating value. The pre-rating value is the average value of the proxy measure from month t-7 to $\mathrm{t}-18$ (with $\mathrm{t}$ being the month when the rating is published). In a similar way we calculate the post-rating value as the average value between month $t+7$ and $t+18$. We repeat the exercise for the matched (control) sample firms. Column 1 reports the difference in the average opacity measure for the post-rating and pre-rating period for the firms that received a rating for the first time (treatment sample). Column 2 reports the difference in the average opacity measure for the post-rating and pre-rating period for the sample of matched firms (control sample). Column 3 reports the difference-in-difference (DID) estimate which is obtained by subtracting the change in opacity measure for each group in treatment sample from the change in opacity measure for the corresponding matched firms. Column 4 reports the standard error for the difference which have been adjusted using the approach outlined by Abadie and Imbens (2012). t-statistic for the difference-in-difference is reported in column 5. The last column reports the number of firms that received a rating for the first time. $* * *, * *$ and $*$ indicate significance at the $1 \%, 5 \%$ and $10 \%$ respectively.

\begin{tabular}{|c|c|c|c|c|c|c|}
\hline \multicolumn{7}{|c|}{ Panel A: Closest 5 Neighbors } \\
\hline & $\Delta$ Treated & $\Delta$ Control & Difference in $\Delta$ & Std. Error & t-Stat & $\mathrm{N}$ of Events \\
\hline \multicolumn{7}{|c|}{ Market Based Measures } \\
\hline $\mathrm{R}^{2}$ & 0.07 & 0.10 & -0.03 & 0.03 & -0.91 & 942 \\
\hline SKEW & -0.01 & -0.01 & 0.00 & 0.03 & 0.05 & 942 \\
\hline CRASH & 0.00 & 0.00 & -0.00 & 0.00 & -0.83 & 942 \\
\hline \multicolumn{7}{|c|}{ Analysts Based Measures } \\
\hline NUMEST & 1.15 & 0.44 & $0.72 * * *$ & 0.14 & 4.99 & 785 \\
\hline DISP & 0.00 & 0.00 & 0.00 & 0.00 & 0.50 & 651 \\
\hline ERROR & 0.01 & 0.01 & 0.00 & 0.00 & 0.42 & 693 \\
\hline REVISION RATIO & 0.02 & 0.01 & $0.01 * *$ & 0.00 & 1.98 & 785 \\
\hline \multicolumn{7}{|c|}{ Liquidity Based Measures } \\
\hline AMIHUD & -0.00 & 0.01 & $-0.01 * *$ & 0.00 & -2.05 & 856 \\
\hline HASBROUCK & -0.00 & -0.03 & 0.02 & 0.02 & 1.01 & 945 \\
\hline \multicolumn{7}{|c|}{ Panel B: Closest 10 Neighbors } \\
\hline & $\Delta$ Treated & $\Delta$ Control & Difference in $\Delta$ & Std. Error & t-Stat & N of Events \\
\hline \multicolumn{7}{|c|}{ Market Based Measures } \\
\hline $\mathrm{R}^{2}$ & 0.07 & 0.08 & -0.01 & 0.03 & -0.34 & 942 \\
\hline SKEW & -0.01 & -0.01 & 0.00 & 0.03 & 0.01 & 942 \\
\hline CRASH & 0.00 & 0.00 & -0.00 & 0.00 & -0.48 & 942 \\
\hline \multicolumn{7}{|c|}{ Analysts Based Measures } \\
\hline NUMEST & 1.15 & 0.51 & $0.64 * * *$ & 0.14 & 4.65 & 785 \\
\hline DISP & 0.00 & 0.00 & 0.00 & 0.00 & 1.28 & 651 \\
\hline ERROR & 0.01 & 0.01 & -0.00 & 0.00 & 0.33 & 693 \\
\hline REVISION RATIO & 0.02 & 0.02 & 0.01 & 0.00 & 1.44 & 785 \\
\hline \multicolumn{7}{|c|}{ Liquidity Based Measures } \\
\hline AMIHUD & -0.00 & 0.01 & $-0.01 * *$ & 0.00 & -2.29 & 856 \\
\hline HASBROUCK & -0.00 & -0.01 & 0.01 & 0.02 & 0.36 & 945 \\
\hline
\end{tabular}




\section{TABLE IX. Propensity Score Matching Diagnostics: S\&P 500 Index Inclusions versus Control Sample}

The panels A and B of this table report mean values for two samples; Treatment and Control. The treatment sample consists of those firms that were included in the S\&P500 index for the first time. The control sample consists of firms that were not part of S\&P 500 index and is constructed using the propensity score matching methodology based on first passage probit model with the explanatory variables provided below. Each observation in the treatment sample is matched with the closet 5 (panel A) or closest 10 (panel B) firms according to the propensity score. The last three columns report the difference in the mean values of key firm characteristics between the treatment and the control sample as well as the $t$-statistic and corresponding p-value. Panel C presents the coefficient estimates from different probit regressions of an indicator variable equal to one if the firm is chosen to be included in the S\&P500 index for the first time (Treatment). The column titled Pre-Match specification (first column) is estimated on the entire sample. Based on the predicted probabilities (propensity score) from this first column probit, a "matched" control sample is constructed using the propensity score matching methodology. The columns titled Post-Match report results from a probit regression that has the same specification as the first column but is estimated on a sample that only consists of the treatment and matched firms. The variables are described in Table I. $* * *, * *$ and $*$ indicate significance at the $1 \%, 5 \%$ and $10 \%$ respectively.

\begin{tabular}{|c|c|c|c|c|c|}
\hline \multicolumn{6}{|c|}{ Panel A: Closest 5 neighbors } \\
\hline Variable & $\begin{array}{c}\text { Treatment } \\
\text { Sample }\end{array}$ & $\begin{array}{l}\text { Control } \\
\text { Sample }\end{array}$ & Difference & t-statistic & p-Value \\
\hline B/P Ratio & 0.36 & 0.37 & -0.01 & -0.47 & 0.64 \\
\hline ROE & 0.05 & 0.05 & 0.00 & 0.44 & 0.66 \\
\hline Leverage & 0.49 & 0.48 & 0.01 & 0.79 & 0.43 \\
\hline Size & 8.04 & 8.07 & -0.03 & -0.40 & 0.69 \\
\hline Standard Deviation & 0.02 & 0.03 & 0.00 & -0.21 & 0.84 \\
\hline Turnover & 1.84 & 1.86 & -0.02 & -0.19 & 0.85 \\
\hline Net Income & 57.45 & 59.85 & -2.40 & -0.48 & 0.63 \\
\hline \multicolumn{6}{|c|}{ Panel B: Closest 10 neighbors } \\
\hline Variable & $\begin{array}{c}\text { Treatment } \\
\text { Sample }\end{array}$ & $\begin{array}{l}\text { Control } \\
\text { Sample }\end{array}$ & Difference & t-statistic & p-Value \\
\hline B/P Ratio & 0.36 & 0.37 & -0.01 & -0.53 & 0.60 \\
\hline ROE & 0.05 & 0.05 & 0.00 & 0.30 & 0.77 \\
\hline Leverage & 0.49 & 0.48 & 0.00 & 0.09 & 0.93 \\
\hline Size & 8.04 & 8.07 & -0.03 & -0.41 & 0.68 \\
\hline Standard Deviation & 0.02 & 0.03 & 0.00 & -0.40 & 0.69 \\
\hline Turnover & 1.84 & 1.83 & 0.01 & 0.09 & 0.93 \\
\hline Net Income & 57.45 & 60.51 & -3.06 & -0.61 & 0.54 \\
\hline
\end{tabular}




\begin{tabular}{|c|c|c|c|}
\hline \multicolumn{4}{|c|}{ Panel C: Propensity Score Matching Diagnostics } \\
\hline & Pre Match & $\begin{array}{c}\text { Post-Match } \\
\text { (Closest } 5 \text { Neighbors) }\end{array}$ & $\begin{array}{c}\text { Post-Match } \\
\text { (Closest } 10 \text { Neighbors) }\end{array}$ \\
\hline \multirow[t]{2}{*}{ Constatnt } & $-5.54 * * *$ & $-1.05 * *$ & $-1.14 * * *$ \\
\hline & $(-21.38)$ & $(-2.13)$ & $(-2.58)$ \\
\hline \multirow{2}{*}{ B/P Ratio } & -0.12 & -0.16 & -0.12 \\
\hline & $(-1.59)$ & $(-1.06)$ & $(-0.95)$ \\
\hline \multirow[t]{2}{*}{ ROE } & 0.54 & 0.06 & 0.08 \\
\hline & $(1.56)$ & $(0.10)$ & $(0.14)$ \\
\hline \multirow[t]{2}{*}{ Leverage } & $-0.21 * *$ & 0.15 & -0.00 \\
\hline & $(-2.12)$ & $(0.79)$ & $(-0.02)$ \\
\hline \multirow[t]{2}{*}{ Size } & $0.35^{* * *}$ & -0.02 & -0.01 \\
\hline & $(15.26)$ & $(-0.34)$ & $(-0.27)$ \\
\hline \multirow[t]{2}{*}{ Standard Deviation } & $2.31 *$ & -0.29 & -1.18 \\
\hline & $(1.93)$ & $(-0.12)$ & $(-0.60)$ \\
\hline \multirow[t]{2}{*}{ Net Income } & $-0.00 * * *$ & -0.00 & -0.00 \\
\hline & $(-9.37)$ & $(-0.39)$ & $(-0.54)$ \\
\hline \multirow[t]{2}{*}{ Turnover } & 0.01 & 0.01 & 0.01 \\
\hline & $(0.46)$ & $(0.24)$ & $(0.51)$ \\
\hline Industry Fixed Effects & $\mathrm{Y}$ & $\mathrm{Y}$ & $\mathrm{Y}$ \\
\hline Treated & 397 & 397 & 397 \\
\hline Control & 369401 & 1985 & 3970 \\
\hline Control (Unique Obs.) & 369401 & 1964 & 3893 \\
\hline pseudo $\mathrm{R}^{2}$ & 0.09 & 0.00 & 0.00 \\
\hline
\end{tabular}




\section{TABLE X. Difference-in-Difference Analysis of Inclusion in S\&P 500 Index}

This table reports the reports the results of a difference-in-difference (DID) analysis of the nine opacity proxy variables described in Table I for two samples: Treatment sample consists of those firms that were chosen to be included in the S\&P 500 index for the first time. The control sample consists of firms that were as likely (based on propensity score matching) to be chosen but were not. The control sample is constructed using the propensity score matching methodology based on first passage probit model with the explanatory variables detailed in Table IX. Each observation in the treatment sample is matched with the closet 5 (panel A) or closest 10 (panel B) firms according to the propensity score. For each measure we first calculate the difference between pre- and post-inclusion values across the treatment group by subtracting the pre-inclusion value from the post-inclusion value. The pre-inclusion value is the average value of the proxy measure from month $\mathrm{t}-7$ to $\mathrm{t}-18$ (with $\mathrm{t}$ being the month in which the firm's inclusion in the index is announced). In a similar way we calculate the post-inclusion value as the average value between month $t+7$ and $t+18$. Column 1 reports the difference in the average opacity measure for the post-inclusion and pre-inclusion period for the firms that were chosen to be included in the S\&P500 index for the first time (treatment sample). Column 2 reports the difference in the average opacity measure for the post-inclusion and pre-inclusion period for the sample of matched firms (control sample). Column 3 reports the difference-in-difference (DID) estimate which is obtained by subtracting the change in opacity measure for each group in treatment sample from the change in opacity measure for the corresponding matched firms. Column 4 reports the standard error for the difference which have been adjusted using the approach outlined by Abadie and Imbens (2012). t-statistic for the difference-in-difference is reported in column 5. The last column reports the number of firms that were chosen to be included in the S\&P 500 index for the first time. $* * *, * *$ and $*$ indicate significance at the $1 \%, 5 \%$ and $10 \%$ respectively.

\begin{tabular}{|c|c|c|c|c|c|c|}
\hline \multicolumn{7}{|c|}{ Panel A: Closest 5 Neighbors } \\
\hline & $\Delta$ Treated & $\Delta$ Control & Difference in $\Delta$ & Std. Error & t-Stat & $\mathrm{N}$ of Events \\
\hline \multicolumn{7}{|c|}{ Market Based Measures } \\
\hline $\mathrm{R}^{2}$ & 0.16 & 0.11 & 0.06 & 0.05 & 1.27 & 397 \\
\hline SKEW & -0.15 & -0.04 & $-0.10^{* *}$ & 0.05 & -2.26 & 397 \\
\hline CRASH & 0.00 & 0.00 & $0.00^{* *}$ & 0.00 & 2.55 & 397 \\
\hline \multicolumn{7}{|c|}{ Analysts Based Measures } \\
\hline NUMEST & 2.37 & 1.23 & $1.14 * * *$ & 0.22 & 5.12 & 388 \\
\hline DISP & 0.00 & 0.00 & 0.00 & 0.00 & 0.41 & 364 \\
\hline ERROR & 0.01 & 0.01 & -0.00 & 0.00 & -0.89 & 361 \\
\hline REVISION RATIO & 0.03 & 0.03 & 0.00 & 0.01 & 0.54 & 388 \\
\hline \multicolumn{7}{|c|}{ Liquidity Based Measures } \\
\hline AMIHUD & -0.00 & 0.00 & $-0.00 * *$ & 0.00 & -2.19 & 386 \\
\hline HASBROUCK & -0.03 & -0.04 & 0.01 & 0.02 & 0.43 & 403 \\
\hline \multicolumn{7}{|c|}{ Panel B: Closest 10 Neighbors } \\
\hline & $\Delta$ Treated & $\Delta$ Control & Difference in $\Delta$ & Std. Error & t-Stat & N of Events \\
\hline \multicolumn{7}{|c|}{ Market Based Measures } \\
\hline $\mathrm{R}^{2}$ & 0.16 & 0.11 & 0.05 & 0.04 & 1.18 & 397 \\
\hline SKEW & -0.15 & -0.03 & $-0.11^{* * *}$ & 0.04 & -2.63 & 397 \\
\hline CRASH & 0.00 & 0.00 & $0.00 * * *$ & 0.00 & 2.61 & 397 \\
\hline \multicolumn{7}{|c|}{ Analysts Based Measures } \\
\hline NUMEST & 2.37 & 1.19 & $1.18^{* * *}$ & 0.21 & 5.60 & 388 \\
\hline DISP & 0.00 & 0.00 & -0.00 & 0.00 & -0.41 & 364 \\
\hline ERROR & 0.01 & 0.01 & -0.00 & 0.00 & -0.74 & 361 \\
\hline REVISION RATIO & 0.03 & 0.03 & 0.00 & 0.01 & 0.56 & 388 \\
\hline \multicolumn{7}{|c|}{ Liquidity Based Measures } \\
\hline AMIHUD & 0.00 & 0.00 & $-0.00^{* * *}$ & 0.00 & -2.58 & 386 \\
\hline HASBROUCK & -0.03 & -0.03 & -0.00 & 0.02 & -0.17 & 403 \\
\hline
\end{tabular}




\section{TABLE XI. Instrumental Variables Test}

The columns 1 through 3 of this table report the results of a 2SLS estimation of the relationship between NUMEST (AMIHUD) and inclusion in S\&P500 index. In the first stage (column 1) the main variable of interest (New Constituent) is instrumented with SIZE DIFF, the absolute difference between each stock size and the size of the smallest constituent of the index. In the second stage the value of each opacity proxy is regressed against the fitted value of New Constituent from the first stage and other control variables. In columns 4-6 we report the results of a 2SLS estimation of the relationship between NUMEST (AMIHUD) and the recent issuance of a rating. In the first stage (column 4) the main variable of interest (Newly Rated) is instrumented with FRAC_RATED, the fraction of firms in the same industry already rated. In the second stage the value of each opacity proxy is regressed against the fitted value of Newly Rated from the first stage and other control variables. All specifications include year and firm fixed effects. $* * * * *$ and $*$ indicate significance at the $1 \%, 5 \%$ and $10 \%$ respectively.

\begin{tabular}{|c|c|c|c|c|c|c|c|}
\hline \multicolumn{4}{|c|}{ New Index Constituent } & \multicolumn{4}{|c|}{ Newly Rated } \\
\hline & $(1)$ & $(2)$ & (3) & & $(4)$ & $(5)$ & $(6)$ \\
\hline & First Stage & Ln(NUMEST) & AMIHUD & & First Stage & Ln(NUMEST) & AMIHUD \\
\hline \multirow[t]{2}{*}{ Constant } & 0.00 & -0.66 & $0.00 * *$ & Constant & $0.06^{* * *}$ & $-0.27 * * *$ & $0.00 * *$ \\
\hline & $(0.80)$ & $(-1.63)$ & $(2.29)$ & & $(9.02)$ & $(-3.88)$ & $(2.21)$ \\
\hline Instrument & & & & Instrument & & & \\
\hline SIZE_DIFF & $-0.14 * * *$ & & & FRAC_RATED & $-0.04 * * *$ & & \\
\hline & $(-10.25)$ & & & & $(-13.39)$ & & \\
\hline $\begin{array}{l}\text { Instrumented } \\
\text { Variable }\end{array}$ & & & & $\begin{array}{l}\text { Instrumented } \\
\text { Variable }\end{array}$ & & & \\
\hline \multirow[t]{2}{*}{ New Constituent } & & $22.59 * * *$ & $-0.01 * * *$ & Newly Rated & & $1.29 * * *$ & -0.00 \\
\hline & & $(10.19)$ & $(-9.12)$ & & & $(6.34)$ & $(-0.13)$ \\
\hline \multirow[t]{2}{*}{ Index Member } & $0.12 * * *$ & $-2.72 * * *$ & $0.00 * * *$ & Rated Company & $0.20 * * *$ & $-0.23 * * *$ & -0.00 \\
\hline & $(164.93)$ & $(-9.97)$ & $(9.37)$ & & $(210.46)$ & $(-5.59)$ & $(-0.12)$ \\
\hline \multirow[t]{2}{*}{ Book to Price } & $-0.00 * * *$ & $0.14 * * *$ & -0.00 & Book to Price & $-0.01 * * *$ & $0.08 * * *$ & $0.00 * * *$ \\
\hline & $(-10.62)$ & $(13.45)$ & $(-0.59)$ & & $(-21.79)$ & $(33.70)$ & (11.05) \\
\hline \multirow[t]{2}{*}{ ROE } & $0.01 * * *$ & $-0.21 * * *$ & $0.00 * * *$ & ROE & $0.01 * * *$ & $-0.10 * * *$ & $0.00 *$ \\
\hline & $(4.28)$ & $(-6.68)$ & $(4.57)$ & & $(7.02)$ & $(-18.48)$ & $(1.84)$ \\
\hline \multirow[t]{2}{*}{ Leverage } & $-0.01 * * *$ & $0.26^{* * *}$ & $-0.00 * *$ & Leverage & $0.00 *$ & $-0.06^{* * *}$ & $0.00 * * *$ \\
\hline & $(-8.98)$ & (5.73) & $(-1.97)$ & & $(1.90)$ & $(-10.93)$ & (12.67) \\
\hline \multirow[t]{2}{*}{ Ln (Market Value) } & $0.00^{* * * *}$ & $0.33 * * *$ & $-0.00 * * *$ & Ln (Market Value) & $-0.01 * * *$ & $0.36 * * *$ & -0.00 *** \\
\hline & $(4.06)$ & $(46.90)$ & $(-12.26)$ & & $(-16.95)$ & (200.04) & $(-17.53)$ \\
\hline \multirow[t]{2}{*}{ Std. Deviation } & $0.16^{* * * *}$ & $-4.39 * * *$ & $0.00 * * *$ & Std. Deviation & $0.04 * *$ & $-0.98 * * *$ & $0.00 * * *$ \\
\hline & $(12.628)$ & $(-9.908)$ & (17.699) & & (2.508) & $(-20.129)$ & $(35.210)$ \\
\hline \multirow[t]{2}{*}{ Turnover } & $0.00 * * *$ & $-0.04 * * *$ & $0.00 * * *$ & Turnover & $0.00^{* * *}$ & $0.05 * * *$ & $-0.00 * * * *$ \\
\hline & (22.69) & $(-3.93)$ & $(4.10)$ & & $(10.90)$ & $(59.16)$ & $(-18.46)$ \\
\hline \multirow[t]{2}{*}{ Excess Return } & $0.01 * * *$ & $-0.32 * * *$ & $0.00 * * *$ & Excess Return & $0.00 * * *$ & $-0.18 * * *$ & $-0.00^{* * * *}$ \\
\hline & $(19.48)$ & $(-19.85)$ & $(5.23)$ & & $(9.08)$ & $(-124.19)$ & $(-12.72)$ \\
\hline Time FE & $\mathrm{Y}$ & $\mathrm{Y}$ & $\mathrm{Y}$ & Time FE & $\mathrm{Y}$ & $\mathrm{Y}$ & $\mathrm{Y}$ \\
\hline Firm FE & $\mathrm{Y}$ & $\mathrm{Y}$ & $\mathrm{Y}$ & Firm FE & $\mathrm{Y}$ & $\mathrm{Y}$ & $\mathrm{Y}$ \\
\hline $\mathrm{N}$ & 504515 & 504515 & 504515 & $\mathrm{~N}$ & 504515 & 504515 & 504515 \\
\hline adj. $R^{2}$ & 0.12 & 0.82 & 0.17 & $\operatorname{adj} . R^{2}$ & 0.18 & 0.76 & 0.17 \\
\hline F-Stat (Instrument) & 105.06 & & & F-Stat (Instrument) & 179.18 & & \\
\hline Prob. F & 0.00 & & & Prob. F & 0.00 & & \\
\hline
\end{tabular}


